ISSN: 0213-2079 - ISSN electrónico: 2386-3889

DOI: https://doi.org/10.14201/shhmo2021431369406

\title{
«SEÑORES DE LA TIERRA». EL «CAMINO VALENCIANO» Y LA GUERRA DE LOS TREINTA AÑOS ${ }^{1}$
}

\section{"Lords of the earth». The "Valencian road» and the Thirty Years War}

Javier HERNÁNDEZ RUANO

Universitat de València

hernandez_javrua@gva.es

Fecha de recepción: 10/11/2020

Fecha de aceptación: 16/03/2021

RESUMEN: La guerra de Mantua-Monferrato (1628-1631), el rompimiento con Francia (1635) y, sobre todo, la rebelión de Cataluña (1640) situaron progresivamente al mediterráneo reino de Valencia en el centro de la logística de la monarquía hispánica durante la Guerra de los Treinta Años. Mientras otros corredores militares colapsaban, el «camino valenciano» fue crucial para el desplazamiento de las fuerzas de Felipe IV y la integración del reino en la Unión de Armas, cuyo máximo exponente administrativo fue la creación de una Junta de guerra en la frontera valenciana. Interpretar las consecuencias militares y socioeconómicas es la finalidad de este trabajo.

Palabras clave: Guerra de los Treinta Años; reino de Valencia; logística; rebelión de Cataluña.

ABSTRACT: the Mantua-Monferrato war (1628-1631), the break with France (1635) and, above all, the rebellion of Catalonia (1640) progressively

1. Proyecto de investigación del Departament d'Història Moderna i Contemporània de la Universitat de València «Privilegio, trabajo y conflictividad. La sociedad moderna de los territorios hispánicos del Mediterráneo occidental entre el cambio y las resistencias», con la referencia PGC2018-094150-B-C21.

Ediciones Universidad de Salamanca / అ@@ Stud. his., H. ${ }^{a}$ mod., 43, n. 1 (2021), pp. 369-406 
placed the Mediterranean kingdom of Valencia at the center of the logistics of the Spanish monarchy during the Thirty Years War. While other military corridors collapsed, the «Valencian road» was crucial for the movement of the forces of Felipe IV and the integration of the kingdom into the Union of Arms, whose greatest administrative exponent was the creation of a Junta of war in the Valencian border. Interpreting the military and socioeconomic consequences is the purpose of this work.

Keywords: Thirty Years War; Kingdom of Valencia; logistics; catalan rebellion.

En el patio de la ermita de Sant Pau de Albocàsser, en el interior castellonense, puede contemplarse un retrato al carboncillo del duque Carlos Manuel I de Saboya pintado en 1585, año de sus esponsales en Zaragoza (Goikoetxea, 2013: 1345). La gallarda pose que exhibe el yerno de Felipe II, desprende el orgullo de una generación de gobernantes partícipes del apogeo de la monarquía hispánica. A otra época distinta remitía el fondo más sombrío de la estancia, donde unos logrados grafitis de las galeras reales (desaparecidos) representaban la desesperada lucha de la Monarquía por preservar su hegemonía en una «guerra total»: la Guerra de los Treinta Años (1618-1648) (Stradling, 1981: 75). Acompañaba a aquellos bajeles en su travesía intemporal un irónico mensaje: «Yo soy el conde de Olivares, rey de España», inestimable testimonio de crítica política grabado seguramente por uno de los miles de soldados que transitó por una de las rutas secundarias de lo que llegó a convertirse en una arteria militar vital. Fue esta una travesía terrestre y marítima utilizada crecientemente desde la crisis de Mantua (1628), que se convertirá en el epicentro logístico de la Monarquía en su hora decisiva. El recurso a la antigua vía Heraclea a su paso por territorio valenciano evitó la pérdida del Principado de Cataluña y, quizás, un colapso definitivo. Su historia es un capítulo más de los intentos del estado moderno por responder eficazmente a la formación de tropas; un espejo, a su vez, del conflicto entre el autoritarismo del estado moderno y las constituciones locales en el siglo XVII. Pero el relato de lo ocurrido en aquella vía durante los años en los que la Monarquía redimensionó sus objetivos en una estrategia de conservación (Hernando, 2013: 64) sería incompleto sin la identificación de las consecuencias sociales y económicas de los continuos tránsitos y alojamientos, que también padecían en la Península los pasos de los Pirineos (Martínez, 2008: 319-383). Por ese motivo es al mismo tiempo la historia de un drama de opresión fiscal, intimidaciones, violencias, reacción social y crisis económica cuyas perniciosas repercusiones aún están por dilucidar (Borreguero, 2018: 434). Los extremos de la devastación de Centroeuropa durante la Guerra de los Treinta Años dieron precisamente título a la obra de Wilson Europe's Tragedy, y a que el autor nos

Ediciones Universidad de Salamanca / @®@@ Stud. his., H. ${ }^{a}$ mod., 43, n. 1 (2021), pp. 369-406 
recordase que la historiografía germana no encuentre otra destrucción mayor en toda la historia de Alemania (2009: 4-6).

Estas consideraciones nos remiten inevitablemente a una cuestión fundamental: las razones del mantenimiento del orden social y político en el reino de València (particularmente en la frontera) pese al encadenamiento de traumáticos desencuentros con las tropas, al contrario de lo que sucedió en el Principado, donde la resultante revolución social campesina antecedió a una revolución política que socavó la soberanía de Felipe IV (Elliott, 2016: 339, 355, 395-424). Efectivamente, «La variedad de esta guerra» - reflexionaba Francisco de Melo- «fue causa de que las tropas y exércitos del rey Católico hubiesen de revolverse muchas veces de unas provincias en otras (...) y que a estos sus tránsitos y pasages se siguiesen los robos...»; más aún - aseveraba - si la jefatura de los abastecimientos no se acomodaba a los medios del país (Melo, 1808: 14, 28). Para el veterano político y militar portugués no cabía duda de cuál había sido el error de cálculo esencial de Felipe IV. Al contrario, la élite de Castilla no cruzó el Rubicón de la rebelión (Elliott, 1991: 102-122) pese a los escalofríos que producían los aposentamientos (Pi Corrales, 1998: 513-530) ni tampoco en Aragón, a pesar del pavor que desataron en la franja oriental de Aragón (Sanz, 2004: 173-208), cuyos pormenores son hitos de los desastres de la guerra (Camarero, 2015: 111). Se alineó de igual modo en Aragón y València (Casey, 1983: 230-254; 96-173 y Gil, 1991: 44-101) pese a que esas tierras soportaron una carga análoga, como en el Maestrazgo viejo de la Orden de Montesa (en adelante Maestrazgo), que conformaba una parte de la frontera valenciana con Cataluña.

\section{LA OPORTUNIDAD DEL «CAMINO VALENCIANO»}

La costa mediterránea había sido para los Austrias hispanos una acostumbrada plataforma de embarque de las tropas en su travesía hacia Italia, más aún desde que en 1568 los holandeses hostigaran la ruta naval cantábrica (Martínez, 2008: 777). Pero fue la guerra con Francia a partir de 1635 la que provocó no solo un aumento exponencial de los tránsitos, sino la definitiva reformulación de la direccionalidad de los flujos de soldados desde que el Consejo de Aragón considerase en 1631 que el embarcadero de Vinaròs era más seguro que el del Grao de València (Felipo, 1988: 119). Los tránsitos primaron, desde entonces, el desplazamiento terrestre con la intención de alcanzar el Principado. Desde la pérdida de Lorena en 1633, las dos rutas centroeuropeas del «camino del Imperio» o «camino español» habían sido asaltadas por las armas borbónicas (Parker, 1991: 116) y cerradas definitivamente tras la expugnación de Breisach en 1639 (Elliott, 2016: 366), que además dejaba

2. Expresión utilizada por F. Spooner en L'economie mondiale et les frappes monétaires en France 1493-1680, París, 1956, p. 25. (Elliott, 2016: 74).

Ediciones Universidad de Salamanca / @®@@ Stud. his., H. ${ }^{a}$ mod., 43, n. 1 (2021), pp. 369-406 
expedito el paso entre Francia y la llanura alemana. El hostigamiento galo había comenzado con la inquietante retención en 1631 de la fortaleza de Pignerolo, en el valle del Po, y continuado tras la ocupación de la Valtelina entre 1635 y 1637 (Negredo del Cerro, 2016: 126, 212, 233). Quedaba así comprometida la razón estratégica principal que había empujado a Felipe IV a intervenir en la Guerra de los Treinta Años, especialmente tras expirar la tregua con Holanda en 1621 (Borreguero, 2018: 128) ${ }^{3}$. Otras alternativas se habían descartado. El potencial trayecto de soldados hacia la rebelde Portugal se pospuso, de manera irrevocable en 1643 en favor del frente catalán (Camarero, 2015: 181). En 1640 quedaba Aragón, pero adentrarse a través del Bajo Cinca, La Litera, el Somontano y Ribagorza resultó aventurado hasta la recuperación de Lleida en julio de 1644. Todas esas variables se conjugaron para convertir la ruta valenciana en el único corredor seguro de la Monarquía durante un lustro. Esta circunstancia, y que emergiera en el momento en que parecían derrumbarse los dominios españoles justifica, más allá del tiempo en que sostuvo a los ejércitos reales, que pueda considerarse un corredor con nombre propio. A pesar de que la historia militar ha vivido la mayor renovación historiográfica en España (Martínez, 2008: 19) la trascendencia de este pasaje mediterráneo no ha sido ni siquiera mencionada, con la excepción de Raquel Camarero (2015: 68). Alguna influencia ha tenido que el interés se haya concentrado en la primera etapa de la guerra o fase bohemia, y, asimismo, que el conflicto haya sido considerado un asunto alemán (Negredo del Cerro, 2016: 19, 29).

La ruta terrestre (fig. 1) se nutría de cuatro ramales principales que desde Aragón y Castilla penetraban en el reino de Valencia, de norte a sur, a través de Morella, Siete Aguas, Moixent y Capdet (fig. 2); itinerarios recogidos en el Repertorio de todos los caminos de España (Villuga, 1546). Morella absorbía contingentes del sur de Teruel; Siete Aguas reunía el grueso de los tránsitos castellanos y de Andalucía occidental que dejaban atrás la Meseta por el paso de Requena. La afluencia en el paso mesetario propició que un oficial real residiera en ambas localidades, registrara el número de soldados y los sustentara, aunque no siempre dispuso de dinero para evitar «gran daño» ${ }^{4}$ a unas villas a las que llegaban después de haber recorrido hasta $600 \mathrm{~km}$ o más ${ }^{5}$ Salvar esa enorme distancia invalidaba el argumento sostenido por Felipe IV

3. Las causas y el desarrollo de la guerra pueden seguirse en Wilson (2009), Negredo del Cerro (2016) y Cristina Borreguero (2018). Esta autora ofrece un amplio estado de la cuestión. Una visión de conjunto sobre la milicia hispana en los siglos XVI y XVII se encuentra en Martínez Ruiz (2008).

4. Archivo General de Simancas (AGS), Guerra Antigua (GA), leg. 1515, Ramírez de Prado al Consejo de guerra, 9/9/1643 y leg. 1502, Ramírez de Prado al rey, 19 y 20/5/1643.

5. AGS, GA, leg. 1502, Ramírez de Prado al rey, 19 y 20/5/1643. Alude al paso de una compañía de Ecija (Sevilla); y leg. 1413, Cárcamo al rey, 5/11/1641. Don Bartolomé Ripoll asistía en Siete Aguas.

Ediciones Universidad de Salamanca / @®@@ Stud. his., H. ${ }^{a}$ mod., 43, n. 1 (2021), pp. 369-406 
FIG. 1. El camino valenciano

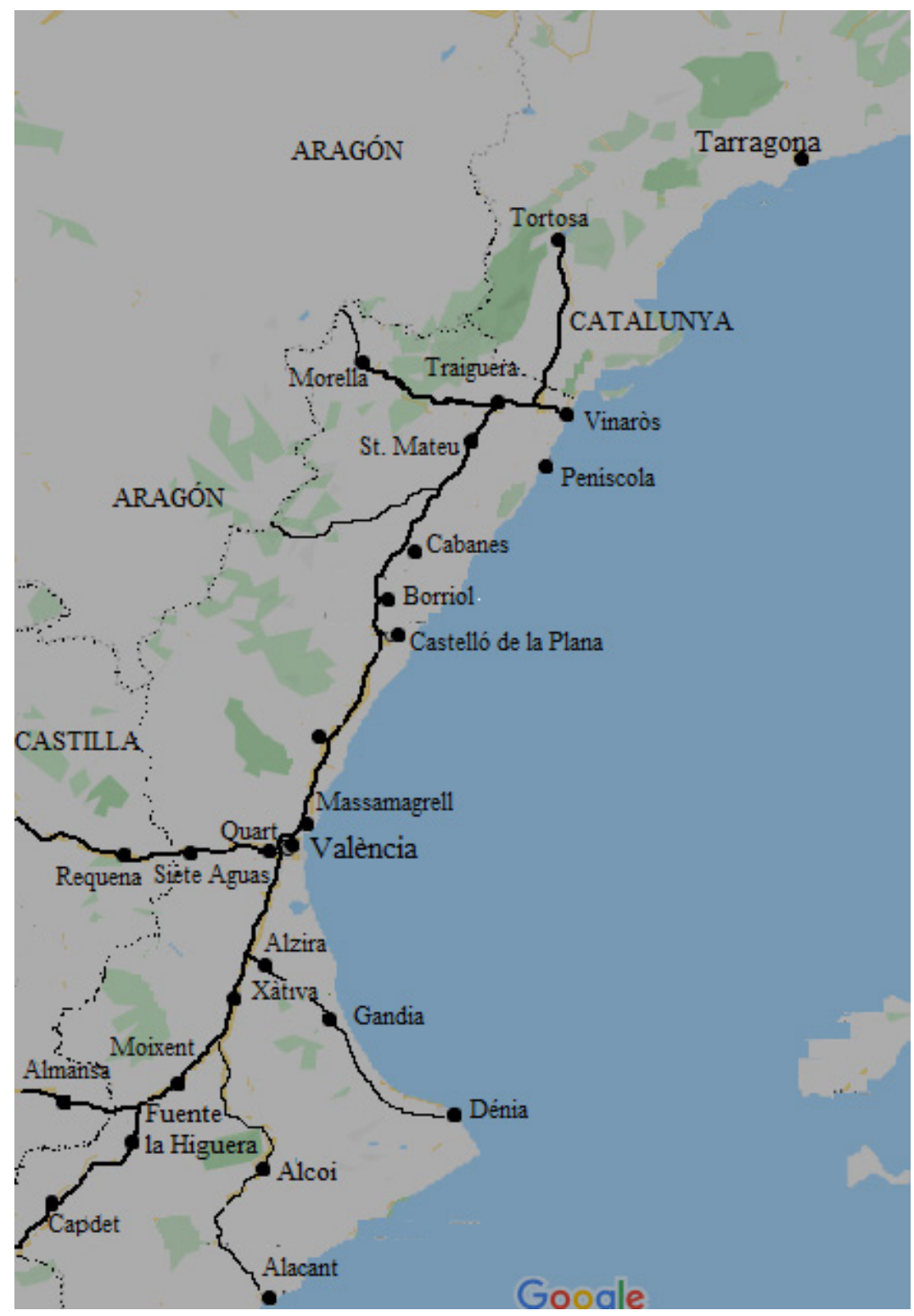

Fuente: elaboración propia.

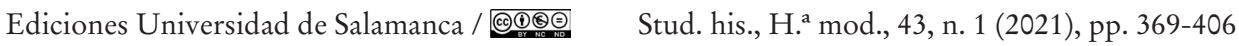


en el decenio de 1630 para no implantar en España el sistema de abastecimiento de las étapes del «camino español» con el pretexto de que las zonas de reclutamiento se encontraban cerca de los puntos de embarque (Parker, 1991: 128). Los reclutas de la Castilla más occidental (Rodríguez, 2013: 190-192) llegaban exhaustos, y la nueva orientación del corredor levantino hacia el Principado amplió el recorrido. El itinerario mesetario contaba con una carretera meridional que transitaba por el puerto de Almansa y discurría, ya en territorio valenciano, por Moixent hacia Xàtiva, en el camino real. Más al sur, Capdet era para su síndico el acceso «més ordinari per a les tropes que pasen de Castella» (presumiblemente de Andalucía oriental) y Cartagena (Guia, 1984: 380-381). Dos grandes vías secundarias regaban ese tronco de comunicaciones, la que bajaba desde las estribaciones meridionales del sistema ibérico, y la que se dirigía hacia Xàtiva desde Alacant-Alcoi y DéniaGandia. Los tránsitos meridionales confluían en Quart, a la vista de València, con los que procedían de Castilla.

Las tropas circunvalaban la urbe capitalina por el norte buscando el municipio costero de Massamagrell, progresando hacia Morvedre (Sagunto) y Nules, ya en la gobernación de Castelló. Al sobrepasar Castelló de la Plana torcían hacia el interior a la busca de Borriol y Cabanes, donde un arco del triunfo romano honoríficofunerario evocaba tanto el pasado glorioso como la larga agonía de la hegemonía hispánica. Las compañías enfilaban entonces hacia Sant Mateu, capital del Maestrazgo, a dos leguas de Traiguera, ya en la raya, desde donde descendían hacia el embarcadero de Vinaròs. Los soldados que hubieran marchado desde Siete Aguas agregaban a su periplo mesetario 27 leguas o $150 \mathrm{~km}$ en tránsitos de dos o tres leguas, salvo en el tramo de Cabanes a Sant Mateu, que constaba de cuatro. Poblaciones ubicadas en la ruta principal como Les Coves o Salzadella también alojaron soldados, pese a no contemplarse, en ocasiones, en el plan de tránsitos ${ }^{6}$. En el decenio de 1640, si cesaba el acoso de los migueletes del maestre de campo Joan Copons, las tropas reanudaban la marcha hacia Tortosa atravesando la encomienda catalana de Ulldecona, en la Castellanía de Amposta, donde el esforzado comendador sanjuanista don Jaume Pertusa escoltaba aquellas cohortes ${ }^{7}$. Una red de angostas sendas convergía con los caminos secundarios. En el norte, la ermita de Sant Pau se hallaba en una encrucijada entre el sur de Teruel, Ares, Benassal, Vistabella, Adzaneta y la costa. El tráfico llegó a ser tan oneroso que Morella solicitó en 1645 que la travesía de las tierras del abad de Benifassà se distribuyera entre los cuatro derroteros de las localidades aragonesas de Pena-roja, Montroig, Aguaviva y Mirambel (fig. 2), esperando desprenderse de parte de los nuevos senyors de la terra (Guia, 1984: 317).

6. AGS, GA, leg. 1460, Los tránsitos que ay de Siete Aguas a Vinaroz, 1642.

7. ACA (Archivo de la Corona de Aragón), CA (Consejo de Aragón), leg. 721, doc. 74/1, don Jaime Pertusa, 29/6/1641 y leg. 564, doc. 11, el virrey Arcos, 27/5/1643. 
FIG. 2. Caminos secundarios del norte

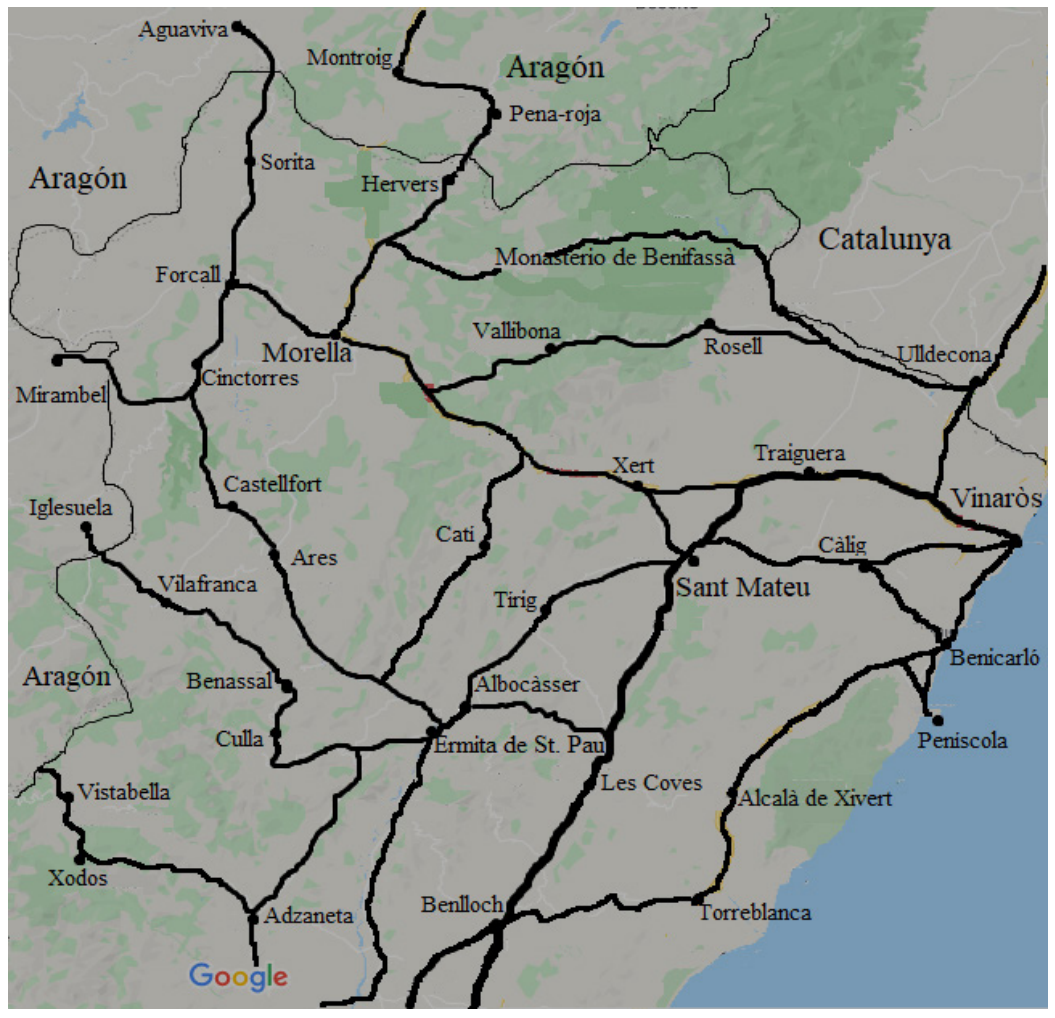

Fuente: elaboración propia.

Las conductas y alojamientos exigían un sistema de abastecimiento que imponía considerables demandas a los consistorios y particulares cuando fallaba la proveeduría real o faltase el dinero, lo que era frecuente. En las antípodas se situaba el bien sufragado procedimiento de las étapes del corredor de Milán a Flandes (Parker, 1991: 90-144). Sin embargo, en la península ibérica la real hacienda ahorró ingentes recursos al responsabilizar del avituallamiento a las fustigadas comunidades rurales una vez desatada la crisis de Mantua-Monferrato en 1628. A partir de entonces, el reclutamiento en territorio valenciano fue progresivamente en aumento. En 1635 (tras la ruptura con Francia) se reclutaban ya más de mil hombres, y en 1639 se alcanzó un hito con cuatro levas (Vila, 1979: 125-142). Esto fue solo una fracción del ingente número de tropas a las que hubo que asistir procedentes de todas las naciones de la Monarquía. 
JAVIER HERNÁNDEZ RUANO

«SEÑORES DE LA TIERRA». EL «CAMINO VALENCIANO» Y LA GUERRA DE LOS TREINTA AÑOS

\section{DE LA CRISIS DE MANTUA-MONFERRATO A LA REBELIÓN CATALANA}

Años de tránsitos, alojamientos e impuestos redoblados habían conducido a la desesperación del campesinado en Centroeuropa, que se rebeló en Westfalia (1622) y la Alta Austria (1626 y 1632) (Wilson, 2009: 533). El incremento de la presión fiscal sobre los campesinos comenzó a sentirse en la Monarquía a partir de la ofensiva naval inglesa y holandesa en 1625 y la consecución de la Unión de Armas, pero sobre todo, tras estallar la perturbadora crisis de Mantua (Elliott, 2016: 275). El acuerdo alcanzado en las Cortes valencianas de 1626 para sufragar durante quince años con 1.080.000 libras tropas «voluntarias» a razón de 72.000 libras anuales fue un triunfo para la Unión de Armas de Olivares (de Lario, 1988: 97-145), al inaugurar la movilización en pos de empresas exteriores. Pero a menor escala, la intermediación privada o «reclutamiento administrativo» había permitido antes a la corona obtener reclutas voluntarios al margen de las Cortes tanto en Castilla como en los reinos de la Corona de Aragón (Thompson, 1981: 146-151) sin recurrir a los cuerpos ordinarios de vigilancia costera (Pardo, 2001: 419-430) o la milicia efectiva (Pérez: 1991). De forma excepcional, València había reclutado dos compañías en 1621 destinadas a una empresa «exterior»: la defensa de Ibiza (Felipo, 1988: 99) cuya relevancia estratégica para los valencianos era equiparable a la de Tortosa. No obstante, siempre hubo una gran desproporción entre la aportación de soldados que se obtenían de la Corona de Castilla (una compañía cada 20.000 vecinos) y los reinos de la Corona de Aragón, que era un 50 \% inferior (Rodríguez, 2013: 193). Por otro lado, el reino no estaba vetado a los tránsitos y alojamientos. Los fueros permitían bajo ciertas condiciones que las poblaciones auxiliaran con un sustento básico a la soldadesca que consistía en casa, cama, agua, lumbre, luz y sal. Otra cosa fueron decisiones unilaterales como la de 1575 , cuando se alojaron dos compañías de caballo castellanas cuya destinación se ocultó (Belchí, 2006: 239).

La travesía marítima comenzó a ser anual desde la primera gran expedición militar a los Países Bajos en 1567, lo que redundó tanto en ventajas como en inconvenientes para la población. Por un lado, los soldados desmandados y el exceso de demanda de provisiones ocasionaban perjuicios. No es extraño que Vinaròs suplicase en 1572 limitar los desembarcos a un día para evitar el desabastecimiento y los alborotos (Belchí, 2006: 23) en una época inaugurada por la evolución anual de las galeras y la llegada a ese embarcadero de cargamentos tirados por mulas con las mesadas que se dirigían a Génova, como el que observó un viajero francés que recorría el reino en 1603 (Elliott, 2016: 129). Algunos segmentos de la población podían obtener ingresos adicionales con la arribada de la $\operatorname{armada}^{8}$, pero sobre todo

8. Entre 1630 y 1631, por ejemplo, se pagaron 606 libras a dieciséis vecinos de Peníscola (marineros, labradores y mercaderes) que incluían 205 libras al proveedor real, un comerciante local (Hernández: 1997).

Ediciones Universidad de Salamanca / అ@@ Stud. his., H. ${ }^{a}$ mod., 43, n. 1 (2021), pp. 369-406 
fueron proveedores como Antoni Borràs de Benicarló o el genovés Cosme Ferrer de Vinaròs los que se enriquecieron durante el reinado de Felipe II (Hernández, 2014: 87-90). Sin embargo, este escenario de equilibrio entre los recursos locales y las demandas de la administración se resquebrajó tras la expulsión de los moriscos y el hundimiento de la economía valenciana (Casey, 1983: 15, 96-103), una cuestión central en la posición de los estamentos durante las Cortes de 1626 frente a las pretensiones iniciales de Olivares (de Lario, 1986: 84-85). La franja septentrional del reino, apenas poblada de nuevos convertidos, no pudo eludir tampoco la «grande quiebra» ${ }^{9}$ y el persistente «colapso económico» de la Orden de Montesa (Andrés, 1999: 55-87; 2006: 227-251). La sucesión de sequías que agostó el mediterráneo occidental desde 1625 a 1628, y de nuevo en 1631, indujo una ininterrumpida crisis de subsistencias (García, 1980: 124) con graves consecuencias sobre el comercio. Semejante contexto socioeconómico fue el caldo de cultivo de la inimicicia entre el campesinado catalán y las tropas del rey (Elliott, 2016: 285, 301, 339).

El deterioro del panorama económico fue ignorado por Olivares cuando se presentó en los reinos peninsulares de la Corona de Aragón en demanda de hombres y dinero en 1626. El acuerdo final en València, el reino más afectado, resultó en un aluvión de memoriales sobre los perniciosos efectos de los impuestos (Felipo, 1988: 42-48), justo en el período en que la guerra de Mantua-Monferrato desarbolaba los planes del valido, sobre todo, porque la tensión en el norte de Italia formaba parte de una cascada de reacciones contra la Casa de Austria al sentirse amenazadas Suecia y Holanda, lo que resultó en siete grandes asedios que parecían presagiar una guerra generalizada (Wilson, 2009: 424). Las primeras reclutas valencianas destinadas al norte de Italia se formalizaron en 1628 con dos compañías (Felipo, 1988: 114). Solo hasta 1637 los reclutamientos habían alcanzado ya alrededor de 13.000 hombres (Casey, 1982: 230). Las compañías de 1631 fueron testigo de la escasez de grano y el incremento del precio de la harina. Incluso en pasos de zonas cerealísticas como Almansa el precio del trigo creció un 63 \% (Arráez, 2015: 41), lo que no auguraba una estancia jubilosa en la València que versara Lope de Vega. La primavera anterior, ya había registrado un motín en Benicarló que frustró un plan oculto del consistorio para mezclar harina con habas, y los vecinos fueron incapaces de alimentar a los soldados. Al interpelar a sus representantes, estos se inclinaron por una prudente distribución de dinero entre anfitriones y huéspedes ${ }^{10}$. Este tipo de incidentes presentaba agrios antecedentes desde el reinado de Carlos I, a pesar de las llamadas en Castilla a los deberes cristianos de las guardas mediante sucesivas Ordenanzas (Martínez, 2008: 623-658). En Valencia existen notables ejemplos: Vila-real (1537)

9. Testimonio del baile general del Maestrazgo en 1612 (Tropé, 1983: 182).

10. ARV, Clero, leg. 935, caja 2471-72, Procés de visita de don Baltasar Sanz a Benicarló (1636).

Ediciones Universidad de Salamanca / అ@@ Stud. his., H. ${ }^{a}$ mod., 43, n. 1 (2021), pp. 369-406 
(Pardo, 2002: 561-585), Xàtiva (1572) (Belchí, 2006: 230) y las principales plazas (1582), que en Peníscola costaron la vida al capitán Francisco Velázquez ${ }^{11}$. De los excesos de las dieciocho compañías alojadas ese año supo Felipe II en las Cortes de 1585 (García, 1980: 152) al denunciarse morts, stupros, raptes, adulteris, furts, latrocinis (...) en gran offensa de nostre señor Deu (Salvador, 1974: 79) pese a que continuaban acantonadas.

Los múltiples frentes europeos, a los que se habían unido los suecos en 1630, convirtieron el servicio aprobado en 1626 en insuficiente, y la pretensión de «disciplinar el gasto», en una quimera (Esteban, 2013: 277). La Monarquía inició, además, una política de reclutamiento inédito de tropas «voluntarias» (Guia, 1984: 27) y búsqueda de recursos que no podía obtener solo mediante asientos, el endeudamiento de las autoridades y nobles. El virrey se empeñó en 1635 con 3.000 ducados para conseguir bastimentos ${ }^{12}$, el duque de Gandía y el gobernador de València en $1637^{13}$, y también los oficiales del ejército. Solo la ciudad de València consignó en 1650 una deuda pendiente de 150.000 escudos desde 1627 más otros 10.000 destinados a la fortificación de Traiguera ${ }^{14}$. Prueba de la continua presión ejercida sobre los municipios son los conflictos suscitados en el seno de sus comunidades entre autoridades locales y privilegiados, que alegaban exenciones para eludir el estipendio. Cervera exigió a la oligarquía que se comprometiese en 1645 tras un derrame demográfico del $30 \%$ que el consistorio atribuyó a levas, donativos, alojamientos, bagajes y fortificaciones ${ }^{15}$.

En octubre de 1632, mientras se negociaban los servicios atrasados de las Cortes de 1585 y 1604 (de Lario, 1986: 317), los comisarios de las tropas conducidas por don Diego de Aranguren advirtieron al Consejo de Guerra que marchaban en estoica formación sin que hubieran visto un real. Los consejeros propusieron acudir a «donativos y otros expedientes», pero la gentil sugerencia fue rechazada de plano por el Consejo de Aragón, con el argumento de que el salario correspondía a la real hacienda. Los regentes zanjaron el asunto con la acostumbrada letanía de que «en Valencia no hay dinero». El virrey encontró bajo las piedras (mediante donativos) 2.634 reales de los 11.462 que necesitaba, pero dos años después todavía no había zanjado la deuda ${ }^{16}$. De haberse activado el procedimiento del donativo la dialéctica del oficial real influía tanto en la consecución de su propósito como la intimidación

11. AGS, GA, leg. 178, 1582, f. 30 .

12. ACA, CA, leg. 558, doc. 17/1, el C. de Aragón, 16/1/1635.

13. ACA, CA, leg. 557, doc. 13/3, el C. de Aragón, 4/11/1639, leg. 556, doc. 14/8, el C. de Aragón, 5/3/1637; doc. 14/10, 28/3/1637.

14. ACA, CA, leg. 559, doc. 22/15, memorial de Valencia, 1650.

15. ACA, CA, leg. 888, 267/1, el C. de Aragón al rey, 19/11/1645 y leg. 891, doc. 116, el C. de Aragón al rey, 1645.

16. ACA, CA, leg. 555, doc. 8/11, el C. de Aragón, 33/8/1634. 
del rango ministerial, aunque aquellas cualidades no siempre las reuniese un mismo magistrado. En el verano de 1632 el disoluto juez de corte Pedro Rejaule fue el responsable de solicitar donativos en la gobernación de Castelló, exceptuando Morella y el Maestrazgo. Se trataba posiblemente de la primera expedición de ese cariz encabezada por un togado valenciano. Rejaule visitó alrededor de 140 lugares en 48 días, recaudando la respetable cantidad de 4.500 ducados, aunque la media por población (32 ducados) tampoco era para presumir. La fórmula retórica, con instrucciones que procedían de Madrid, era simple: la defensa de la Monarquía ahuyentaba la guerra en casa. Pero el argumento se debilitará tan velozmente como la evidencia de que el mundo había cambiado (Ruiz Ibáñez, 2019: 276):

...representando la necesidad en que Su Magestad se hallaba por las guerras extranjeras que le molestavan, como hasiendo descripción de su entendida monarquía, en el gobierno de la qual consumía en forçossas expensas gran parte de su real patrimonio advirtiéndoles que, si teniendo entonces las guerras tan lexos les alcançavan yguales molestias como las presentes, qué sería si las tubiessen dentro de España, que era lo mismo que en sus casas... ${ }^{17}$.

La afluencia de levas hacia los pasos fronterizos ocasionó inevitables incidentes. En marzo de 1633, una delegación de Almansa acudió al hospital local para negociar con un soldado que había sufrido la cólera del hidalgo don Martín de Ossa, víctima recurrente de la invasión de su huerto. A cambio del perdón le ofrecieron 500 reales de vellón, los gastos de hospitalización y «vestido de paño pardo nuevo de la tierra, calzón y ropilla y ferreruelo, çapatos y un jubón de lienzo y sombrero y dos camissas nuebas...»; cualquier cosa se antojaba insuficiente para aplacar la furia de los camaradas. La conflictividad había empeorado allí desde que el 6 de abril de 1632 se acuartelara una coronelía de tres compañías de caballería veterana al mando del conde-duque, convertida dos años más tarde en la conocida coronelía de la Guarda del Rey, presta a entrar en acción en València o Cataluña ante cualquier eventualidad (Arráez, 2015: 33, 41). Esta caballería fue responsable de los dolores de cabeza que hubo de soportar el virrey en el invierno 1634 al ser requerido para socorrerla mediante donativos y armas ${ }^{18}$. Sin remedio, las exigencias de las tropas se recrudecían tanto como las dificultades para darles satisfacción.

La leva del servicio que unos meses antes debía engrosar el ejército del cardenal infante se hubiera deshecho a un tiro de piedra de la raya si las arcas de Sant Mateu, Cervera y Benicarló no hubieran desembolsado 400 libras. El acuerdo fue posible al interceder un mercader y caballero de Peníscola, don Baltasar Sans, síndico en las

17. ACA, CA, leg. 891, doc. 3/13, escribano Pedro Juan Avellaneda, notario. La referencia aparece en un documento posterior del 21/10/1641.

18. ACA, CA, leg. 555, doc. 8/15 y 8/16, el rey al C. de Aragón, 28/11/1634.

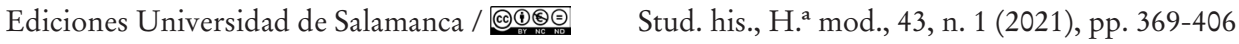


Cortes de 1626, factótum de la administración militar en la región con la cooperación del alcaide de ese castillo, don Gerónimo Valls y Cubells, gobernador de Castelló y eficiente caballero calatravo que sacará de más de un apuro a las tropas reales mediante ágiles operaciones de suministro ${ }^{19}$. El Consejo de Aragón, ávido de comportamientos ejemplares que suplieran las insuficiencias de la administración militar y la falta de compromiso, apremió a que se le concediera a Sans una merced para que «no falte quien le imite...» ${ }^{20}$. Unos meses después del comprometido socorro a la leva de 1634 fueron auxiliadas cuatro compañías valencianas gracias a 1.000 libras que el virrey consiguió recaudar en Alcoi y Castelló de la Plana ${ }^{21}$. También lo fue, gracias a Sant Mateu, una compañía de 600 soldados castellanos destinados a Milán que había penetrado en el camino valenciano por la ruta de Requena ${ }^{22}$. Ese año cobró estatuto legal el donativo, siempre que fuese voluntario (Guia, 1984: 27), lo que no dejaba de ser un recurso retórico para guardar cierta apariencia de foralidad y un hito en la extracción de recursos del reino.

Efectivamente, el coste de las guarniciones, bagajes, alojamientos, donativos y otros gastos derivados de los tránsitos de las levas (al margen del servicio) y tropas de naciones estaba siendo asumido por la sociedad local o las autoridades militares a su costa. Morella había cumplido hasta 1639 con los gastos de la leva (10.000 libras) pero en ese mismo año hubo de costear 32 hombres destinados a Perpignan ${ }^{23}$, y desde 1641 mantenía a 25 soldados en el castillo ${ }^{24}$. Otras cantidades empleadas en fortificaciones, tránsitos y el hostigamiento a los migueletes que merodeaban en la Tinença de Benifassà ${ }^{25}$ son, por ahora, una incógnita. En Peníscola, la otra llave que guarnecía el norte del reino (Hernández, 2014a) la «pobre gente» de la guarnición fue literalmente rescatada de la inanición en 1647 por el infortunado gobernador Francisco Tomás con 15.000 reales. Al año siguiente, con siete años en el cargo, aseguraba haber contribuido con 25.000 reales de «crédito propio» en el socorro a las tropas y fortificaciones, de los que había recuperado solo 5.00026. Su desdichado sucesor, Isidoro Sanz, después de desembolsar 1.000 reales en tales menesteres, no tardó en pedir el relevo ${ }^{27}$. El caballero de Montesa morellano frey don Francisco Ciurana, en calidad de lugarteniente de esa Orden y maestre de campo, seguramente

19. ACA, CA, leg. 886 , doc. $191 / 3$.

20. ACA, CA leg. 652 doc. 87, el C. de Aragón al rey, 26/3/1636.

21. ACA, CA, leg. 558, doc. 17/5, el C. de Aragón, 21/1/1635; doc. 17/2, 14/5/1635.

22. ACA, CA, leg. 891, doc. 3/4, notario Avellaneda, 21/10/1641, 3/14, el rey al virrey, $7 / 8 / 1636$.

23. ACA, CA, leg. 657, doc. 60/1, el C. de Aragón, 24/9/1639.

24. ACA, CA, leg. 724, doc. 3/3, el virrey Arcos, 26/4/1644.

25. ACA, CA, leg. 895, 64, el C. de Aragón al rey, 9/2/1650.

26. ACA, CA, leg. 726, doc. 76; leg. 727, doc. 109/1, el C. de Aragón, 1/6/1649; leg. 893, el C. de Aragón, 24/4/1646.

27. ACA, CA, leg. 555, doc. 8/31, el C. de Aragón, 19/4/1657. 
empleó grandes dispendios en persuadir a los naturales para las levas de Fuenterrabía y Salses, al marchar con un tercio a Tortosa (1643), al socorrer al ejército que acampó en la Castellanía (1645), buscar empréstitos y embargar bastimentos (50.000 arrobas de vino en una ocasión $)^{28}$. Don Andreu Monserrat, su antecesor, había contribuido hasta 1638 con 10.000 libras $^{29}$. Los lamentos de la nobleza y el escaso entusiasmo de los montesianos para combatir en el Batallón de las Órdenes (Andrés Robres, 2019), todo un ejemplo del «eclipse castrense» de las Órdenes Militares (Martínez Ruiz, 2008: 673) contrasta con el interés de acaudalados burgueses locales por capitanear las milicias, conceder préstamos o donaciones en su aspiración de pertenecer a la pequeña nobleza. Los vecinos de Vinaròs Juan Bautista Prima, Josep Ferran y Joan Baptista Sabater, satisficieron sus pretensiones sociales concediendo, el primero, un préstamo de 5.000 libras ${ }^{30}$, el segundo, sosteniendo una compañía de caballos que operaba antes de $1640^{31}$ (acogiéndose a una oferta de privilegios «en particular en la Corona de Aragón») ${ }^{32}$ y, el tercero, prestando la inusitada cantidad de 100.000 reales en pagos fraccionados, sin interés, sin los que «no se hubieran socorrido a tiempo las playas de Tortosa, Tarragona y Rosas...» ${ }^{33}$.

El rompimiento de la guerra con Francia en 1635 marcó el momento en que «comenzó a temblar Europa» (Melo, 1808: 5). París había llegado a la convicción de que solo una guerra directa podía arruinar el predominio de las armas del eje Madrid-Viena, que el año anterior había acordado una campaña militar conjunta, por vez primera, aunque de corto recorrido, saldada con el triunfo de Nördlingen (Negredo del Cerro, 2016: 182, 198). Una oleada de exacciones anegó entonces los reinos hispánicos. Era una abrumadora «fiscalidad paralela» que afectó singularmente a las provincias italianas, sin contar las levas, armas, municiones y abastecimientos (Maffi, 2019: 29-63). Lo que había sucedido hasta ahora en el corredor valenciano era solo una mínima expresión de lo que estaba por venir, con alojamientos recurrentes de una magnitud jamás vista, al igual que en Cataluña y la extensa frontera oriental castellana: «La ocassión presente de la guerra con Francia y otras que se pueden ofrecer» [¿una invasión de la península ibérica o una rebelión?] me a obligado a hordenar que en las rayas de los reynos de Aragón y Balençia se pongan diez y seis mil armas...». La carta real leída en Almansa convertía ese paso en cuartel antes de transformarse en plaza de armas en 1640 (Arráez, 2015: 33-34). Dos años después de la guerra con Francia suponía ya un esfuerzo hercúleo reclutar hombres incluso para la caballería de la costa, pues «tienen aprehendido que estos rumores son para

28. ACA, CA, leg. 892, 97.

29. ACA, CA, leg. 888, 165, el C. de Aragón al rey, s.f.

30. ACA, CA, leg. 903, doc. 35/3, el C. de Aragón, 8/5/1656.

31. Arhivo Histórico Nacional (AHN), Nobleza, Osuna, 18, 9, Josep Ferran, 1/8/1642.

32. ACA, CA, leg. 555, doc. 8/4, Ruiz Ezcaray, secretario del C. de Guerra, 15/7/1634.

33. ACA, CA, leg. 893, doc. 35/4, el virrey Arcos, 17/8/1643. 
sacarlos con engaño de sus casas...» $»^{34}$. Sabían que el año anterior había sido enviada a Navarra ${ }^{35}$. Las comunidades locales manifestaban, por entonces, evidentes síntomas de agotamiento, más que manifiestos en Alzira, a la que apartó de sus tránsitos un prudente comisario «por allar los ánimos mal dispuestos»"

La ofensiva francesa de 1638 desató la presión sobre la frontera pirenaica y espoleó la movilización de los reinos peninsulares de la Corona de Aragón a comienzos de julio para el «ejército de Burgos». Mil seiscientos valencianos entraban en Fuenterrabía al mes siguiente, atacada en un intento de evitar la activación de la ruta del Canal de la Mancha (Wilson, 2009: 651). Antes de terminar el año, una leva del 1 $\%$ (nuevo expediente para la recluta) condujo mil trescientos hombres a Cataluña al mando del veterano de Flandes e Italia don Galcerán Mercader, comendador montesiano de Vilafamés ${ }^{37}$. El deplorable estado de esa expedición levantada in extremis por una administración irresponsable desencadenó un espinoso motín en Peníscola, donde los soldados entablaron una batalla con armas de fuego con los vecinos, auxiliados por milicias comarcanas como si se tratara de un desembarco berberisco. Tras la mediación del capitán don Bernardo de Soto las tropas se alojaron en las proximidades al aborrecer ese presidio ${ }^{38}$. Las condiciones con las que marcharon las compañías que les siguieron a finales del verano fueron aún peores si cabe. Entre muertos y fugados, de las 650 tropas iniciales, solo permanecían en pie algunas decenas de enfermos ${ }^{39}$.

La invasión del Rosellón por el príncipe de Condé en 1639, y la vasta operación puesta en marcha para la recuperación de Salses, dotó al reino de Valencia de mayor protagonismo en una guerra que estaba militarizando sus recursos, que iba a convertirlo en un enclave geoestratégico primordial para el socorro de los Condados ${ }^{40}, \mathrm{y}$ único para la recuperación del Principado desde 1640; más aún cuando Fernando III había retirado sus tropas de Alemania occidental para hacer frente a una ofensiva sueca, debilitando la posición del ejército de Flandes. España se quedaba además sin flota de guerra en las Dunas, mientras los franceses tomaban Turín y el paso de Breisach (Negredo del Cerro, 2016: 248), descalabrando dos posibles opciones

34. ACA, CA, leg. 557, doc. 12/1, el virrey al C. de Aragón, 12/4/1637.

35. ACA, CA, leg. 557, doc. 12/5, el C. de Aragón, 25/8/1637.

36. ACA, CA, leg. 891, doc. 3/11/1637.

37. ACA, CA, leg. 564, doc. 11/4-17, el C. de Aragón, 3/7/1638 a 10/11/1638; leg. 558, doc. 4/13; servicios: ACA, CA, leg. 893, doc. 140/1, el C. de Aragón, 26/8/1647.

38. Leva de «poniente»: AGS, GA, leg. 1360, el virrey de València al rey, 8/3/1639 y 12/4/1639. Motín: ACA, CA, leg. 558, doc. 10/1, el C. de Aragón al rey, 30/5/1639. Bajas: ACA, CA, leg. 557, doc.13/31, el C. de Aragón al rey, 8/10/1639.

39. ACA, CA, leg. 557, doc.13/31, el C. de Aragón al rey, 8/10/1639.

40. ACA, CA, leg. 558, doc. 4/48, el rey al virrey de València, junio/1639. El virrey de València debía corresponderse con el protonotario y el gobernador de Castelló. ACA, CA, leg. 558, doc. 4/58, el virrey al rey, 26/9/1639.

Ediciones Universidad de Salamanca / 요 Stud. his., H. ${ }^{a}$ mod., 43, n. 1 (2021), pp. 369-406 
para el desplazamiento de soldados. Desde un ángulo económico, la Monarquía se había erigido por entonces en un estado fiscal-militar en el sentido que González Enciso utilizase para la España del siglo XVIII, cuando la guerra transformó la recaudación de impuestos y la administración (Enciso, 2008: 271-295). No faltarían argumentos para sostener que las desmedidas demandas de numerario disfrazadas de donativos eran las propias de un estado confiscatorio (que guardaría las formas legales) o incluso expoliador (sin someterse a la ley), al soslayar sistemáticamente las constituciones locales y agostar los recursos de sus reinos. Los ignotos expedientes utilizados y las extraordinarias cantidades arrancadas a Castilla o al pozo sin fondo en que se habían convertido las fieles provincias italianas dan esa impresión. Los acontecimientos futuros no aliviarán aquella losa sobre ciudades y comunidades rurales. El rey dio en 1639 la enésima vuelta de tuerca a Aragón y València al exigir un socorro adicional de 500 hombres (pagado por el tesoro real) y recursos para la recuperación de Salses ${ }^{41}$, mientras los catalanes desplazaban al frente 9.000 tropas (Elliott, 2016: 379). «Ningún reino de la Corona» (exceptuando Cataluña debió puntualizar el virrey de València) «ha servido en esta ocasión con más presteza, con más quantidad de gente, pólvora y forrajes...» ${ }^{42}$, sin ni tan siquiera sospechar que de manera inminente iba a suceder «el más siniestro accidente de la monarquía»: la guerra dentro de España (Melo, 1808: 80).

\section{DILUVIO DE TERCIOS Y GALERAS (1640-1642)}

Los enfrentamientos entre la población rural y los tercios en el campo catalán durante la primavera de 1640 aconsejaron suspender la leva en el reino de Valencia (Guia, 1984: 29). La decisión se tomó pensando en un estado de ánimo que en mayo pudo haber inducido la muerte por arcabuzazo del alguacil de la leva de Castelló de la Plana ${ }^{43}$. Pese a todo, el mismo mes la corona arriesgó al conducir tropas castellanas y portuguesas a través del corredor valenciano ${ }^{44}$, escogido pronto para que avanzase por su itinerario más septentrional el ejército del marqués de los Vélez hacia Cataluña, tras desestimarse la entrada menos segura de Aragón (Camarero, 2015: 28). Marchando desde Zaragoza alcanzó Aguaviva y, dejando atrás Aragón, acampó en Morella a comienzos de septiembre (Melo, 1808: 230, 235), aunque desde finales de agosto algunas compañías se acantonaron en el Maestrazgo ${ }^{45}$.

Una pequeña parte del avituallamiento inicial había ocupado a los ministros reales en Vinaròs, donde acudió don Luis de Monsuar, baile general de Cataluña

41. ACA, CA, leg. 557, doc. 13/29, el rey al C. de Aragón, diciembre 1639.

42. ACA, CA, leg. 557, doc.13/31, el C. de Aragón, 8/10/1639.

43. ACA, CA, leg. 718 , doc. 43, Valls y Cubells, 27/5/1640.

44. ACA, CA, leg. 719 , doc. 67/2, el virrey al rey, 8/5/1640.

45. AGS, GA, leg. 1363, el virrey al rey, 28/8/1640. 
una vez refugiado en el monasterio de Benifassà tras el motín de Tortosa del 21 de julio que había defenestrado a la guarnición (Elliott, 2016: 499). Allí había desembarcado don Juan de Garay, maestre de campo general, derrotado en los Condados. Asistían en la villa los jueces de corte valencianos Pedro Villacampa y Pueyo y Miguel Jerónimo Sanz, más el capitán y proveedor don Cristóbal de Cardona, a las órdenes del veedor y contador don Francisco Díaz de Navarrete ${ }^{46}$. Un vecino, Josep Ferran, hacía las veces de proveedor y $\operatorname{contador}^{47}$. Se esperaba que la experiencia del socorro de Salses facilitara el abastecimiento del pan de munición desde Vinaròs al paso del ejército de los Vélez por el Maestrazgo, aunque los soldados de la época eran conscientes de que debían «vivir sobre el terreno» (Borreguero, 2018: 311-314). La planificación fue un fiasco y desató una espiral de saqueos. La impericia del proveedor general, la improvisación (el virrey alegó en su descargo que había sido prevenido con tres días de antelación) y la temeraria inercia de confiar en la despensa local, provocaron la falla del sistema de aprovisionamiento. La cautela de las estupefactas autoridades locales ante aquel aluvión de tercios se malbarató, según una información de testigos, por la «poca prevención que hubo en la provisión del pan ${ }^{48}$. Precisamente la persistente desatención de las líneas de abastecimiento condicionó el resultado de ese «hambriento» ejército ante Montjuïc (Camarero, 2015: 33-34, 178), aunque es probable que el número real de tropas influyera en el desenlace. El marqués de Villafranca estimó que el ejército marchó con 22.800 infantes y 2.800 caballos (Camarero, 2015: 28), pero es muy posible que las bajas y deserciones lo redujeran a una fuerza menor, lo que explicaría mejor la precipitada retirada. Es una conjetura que se desprende de los contingentes que se acantonaron en el Maestrazgo antes de entrar en Cataluña: cinco mil hombres en Sant Mateu, tres tercios de infantería en Xert, Traiguera y Canet lo Roig, dos mil hombres en Salzadella, seis compañías de la armada del Océano y nueve compañías de caballería en Càlig, catorce compañías de infantería valona y tres de caballos en Cervera, un tercio de infantería en Rosell, seis o siete compañías de caballos con infantería en la Jana y siete compañías de caballos en Benicarló ${ }^{49}$, más otros 500 caballos que aguardaban en el camino a Tortosa (Melo, 1808: 235). En total 17.000 infantes y 3.000 caballos; como mucho 20.000 hombres.

Algunas violencias de las armas católicas fueron ruindades gratuitas, como las muertes de un vecino de Benicarló por un pistoletazo (al no quitarse el sombrero al pasar por un puesto de guardia) o la de un vecino de Càlig a espadazos por la

46. AGS, GA, leg. 1382, la Junta de Ejecución al rey, 31/1/1641.

47. AGS, GA, leg. 1362, Ferran a Contreras, 10/10/1640.

48. AGS, GA, leg. 1402, s.f.

49. AGS, GA, leg. 1402, el virrey al rey, 22/1/1641. AGS, GA, leg. 1363, el virrey al rey, 28/8/1640. Hemos considerado una media (por arriba) de 1.000 hombres para los tercios de los que no se cita el número de soldados.

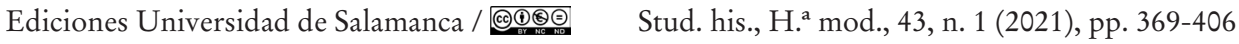


sospecha de haber hurtado dos mulas. Otras bellaquerías se cometieron bajo el silencio cómplice del oidor de la caballería de las Órdenes. Càlig fue afortunada tras acoger las primeras unidades de infantería de la armada del Océano procedentes de La Coruña, pues se detuvieron solo tres jornadas, pero el infortunio sobrevino tras un mes soportando nueve compañías de caballería que se lanzaron al pillaje, aunque la peor parte se la llevó Sant Mateu:

«...les obligaban a dar todo lo necesario para su sustento y de sus caballos, y de las mulas del tren de artillería y carretería. Y que los maltrataban de obra y palabra llevándoles por fuerça quantas alajas tenían en su casa. Hurtaban el ganado, y en los caminos les quitaban las capas. Y quanto le hallaban les rompían los cassares y quemaban la madera. Y que por aver faltado el pan de munición, y no acudir el proveedor general hubo la dicha villa de darles el trigo que tenía para su sustento, con que se halla hoy con gran pérdida por el gasto y subido precio que tiene...»

Tras la derrota en Montjuï, los infamados tercios y la no menos confusa corona (que digería con pesadez el desgarro de Portugal) se vieron forzados a una comprometida posición defensiva. Durante los días lúgubres del aislamiento del ejército real en Tarragona, cuando los obispos valencianos costearon la contratación de médicos y medicinas ${ }^{50}$, la situación de Fernando III parecía seguir el fatal destino de su primo Felipe IV. A lo largo de 1641 una incontenible ofensiva sueca desbarató el sistema de defensa imperial (Negredo del Cerro, 2016: 265). Era el crítico telón de fondo en el que se desenvolvían entonces los tránsitos en un concurrido «camino valenciano» que mantenía la esperanza de contener a los franceses. De momento, el corredor sirvió para auxiliar al desvencijado ejército real ${ }^{51}$ acaparando vituallas, aunque fuera "por menudo» ${ }^{52}$ y presidiar Tortosa con valencianos, que lo harán desde entonces anualmente al considerarla su último bastión. Al igual que Vinaròs, el puerto de Los Alfaques, en el delta del Ebro, resultó determinante para salvar la comprometida situación (Camarero, 2015: 68).

Además de los oficiales reales concentrados en Vinaròs, los artífices de la conservación del ejército fueron el virrey, duque de Medinaceli, y el experimentado marqués de Leganés, exgobernador de Milán, designado ex profeso comandante de las tropas en la raya. Además, hallaron la fórmula para socorrer simultáneamente los Condados. Con la participación del resto de plazas y provincias mediterráneas, el reino de València iba a centralizar la circulación de tropas de naciones, el abastecimiento al ejército real y las plazas catalanas fieles. Felipe IV dio un espaldarazo definitivo a la posición logística de Vinaròs al crear, en el verano de 1641, una Junta de guerra

50. ACA, CA, leg. 559, doc. 12/4, el C. de Aragón, 24/4/1641.

51. ACA, CA, leg. 888, doc. 111/3-9, Valls al C. de Aragón, diciembre 1641.

52. ACA, CA, leg. 559, doc. 12/5-6, el C. de Aragón, 2/6/1641. 
presidida por el veedor general Diego de Eraso y Cárcamo, que en sus funciones disfrutará de los poderes de un «inspector general» solo supeditado al virrey y el capitán general (Borreguero, 2013: 128), fray Alonso Vázquez Miranda, abad de santa Anastasia en Sicilia y confidente del marqués de Leganés, más el maestre de campo Antonio Gandolfo, que había acompañado a Leganés junto a otros ingenieros de la escuela milanesa (Hernández, 2019). La Junta contará con la capacidad defensiva de la cercana traza italiana de Peníscola y sus almacenes, formando un eje logístico que actuaba en coordinación con el gobernador de Castellós3 , el virrey de Valencia, los Consejos de Guerra, Hacienda, Aragón y la Junta de Ejecución. El futuro de la Monarquía quedaba, en alguna medida, ligado a una Junta que iba a coordinar la logística y el pago de las tropas desde el «camino valenciano», la única arteria que podía suministrar oxígeno al tambaleante gigante hispano, como muestran las 5.000 tropas castellanas y un tercio napolitano que se unirán a los valencianos en Tortosa ese verano (Camarero, 2015: 94-95).

El doble socorro naval de Tarragona en el verano de 1641 se sirvió de los almacenes de Vinaròs y Peníscola, con la inestimable participación de sus habitantes, como Francisco Palau, comisario supervisor del embarcadero de Vinaròs, por cuyos servicios y gastos (incluyendo el reconocimiento de la costa catalana y el socorro de 200 caballos sardos) solicitó 5.000 reales $^{54}$. Esta formidable reunión de flotas fue un hito en la logística naval del corredor marítimo, desde el que las galeras y armadas española e italiana allegaron incesantemente hombres y recursos junto a una miríada de naves menores, entre las que resaltaron siete falucas napolitanas. Lógicamente tal reunión de soldados exigía no desatender sus demandas y prevenir conflictos. Durante el desarrollo del socorro se alojaba en la frontera (sobre todo en Vinaròs) la caballería desmontada del Rosellón, a la que se encomendó su protección $\mathrm{n}^{55}$, y el tercio napolitano destinado a Tortosa que se había detenido en la frontera (Camarero, 2015: 95). Cabalgaban con los napolitanos dos hermanos infames, don Pedro y don Mucio Espatafora, siniestros protagonistas de los desmanes desatados en la campiña catalana el año anterior (Melo, 1808: 32) y convertidos en heraldos de la fatalidad. Su maestre de campo Leonardo de Moles, excomulgado por el obispo de Girona y arrestado tras la destrucción de Riudarenes (Elliott, 2016: 432), acabó disfrutando de la paz eterna en un convento agustino de Vinaròs en 1648, junto a otros notables militares y eclesiásticos más piadosos, como fray Tomás de Herrera, confesor de don Juan de Austria (Bover, 2006: 15). Los Espatafora asesinaron en

53. ACA, CA, leg. 558, doc. 4/50, el C. de Aragón al rey, 8/10/1639 y 4/63. ACA, CA, leg. 888, doc. 111/3, legajo 889, doc. 73/1, Valls y Cubells al rey, y legajo 884, 148/1, Valls al C. de Aragón, octubre 1642. La recompensa para Valls y Cubells no llegó sino hasta su retiro en 1648: ACA, CA, leg. 605, doc. 25/27, el Consejo de Aragón, agosto 1648.

54. ACA, CA, leg. 890, doc. 2/1, el C. de Aragón, noviembre 1645.

55. ACA, CA, leg. 559, doc. 15/1, marqués de Leganés, 11/6/1641. 
Benicarló a un vecino que frustró un intento de violación. El escándalo desató la ira popular y un motín secundado por el consistorio, bajo el inquietante grito de ivisca la terra $i$ visca la vila!. Aleccionados los culpables se les encerró primero en Peníscola y después en Xàtiva para causar «terror» a los soldados, pero el virrey no perdonó la actitud tumultuaria del escribano, al que procesó con el propósito de causarle «peor burla que a los capitanes...» ${ }^{56}$.

En octubre se reanudó la operación para el socorro de los Condados con la incorporación a la defensa de la frontera desde Sant Mateu del veterano alemán Juan Jorge, barón de Seebach, hasta entonces jefe del regimiento de alemanes del ejército de los Vélez ${ }^{57}$. El gobernador de Castelló de la Plana participó, como había hecho desde la década anterior, en los suministros de ganado y cabalgaduras ${ }^{58}$. De las versátiles tareas que debía solventar la Junta de Vinaròs es un buen ejemplo la petición de don Enrique de Benavides, capitán de la escuadra de Sicilia, que esos días solicitaba impedimenta para su desnuda infantería ${ }^{59}$. Eran contingencias que, en ocasiones, requerían de imaginativas improvisaciones. Durante el socorro de Rosas en 1643 arribaron a Vinaròs inopinadamente trece galeras napolitanas con el duque de Amalfi, 1.300 alemanes, sus mujeres e hijos, tal y como acostumbraba esa nación ${ }^{60}$, a los que se alojó apresuradamente en el Maestrazgo. El verano anterior algunos vecinos bucearon bajo las quillas de 25 naves de guerra para evitar su hundimiento ${ }^{61} \mathrm{o}$ tuvieron que terraplenar los bastiones de Peníscola durante los domingos «sin costa de la real hazienda ${ }^{62}$.

Mientras se transportaban suministros al Rosellón a comienzos de la primavera de 1642 la Junta afrontó su primera prueba de fuego: la amenaza de invasión. El flamante virrey de Cataluña, La Mothe-Houdancourt, cercó Tortosa en abril, y los migueletes escaramucearon en las inmediaciones del monasterio cisterciense de Benifassà. La resistencia de la ciudad del Ebro, y la capacidad que demostró el marqués de Leganés para abastecer un ejército de socorro que se incrementaba a marchas forzadas en la frontera, hizo desistir al francés. «Se innova a cada instante» reconocía el virrey ${ }^{63}$, cuya inquietud se disipó al conocer que 11.500 tropas distribuidas en junio entre Alcanar, Vinaròs y Peníscola defendían la raya (Camarero, 2015: 152); una hazaña de intendencia si tenemos en cuenta que en Morella, «granero

56. ACA, CA, leg. 720, doc 84, el virrey al rey, Vinaròs, 26/9/41.

57. AGS, GA, leg. 1407, el duque de Medinaceli al marqués de la Inojosa, 15/10/1641. AGS, GA, leg. 1407, Medinaceli a Seebach, 15/10/1641.

58. ACA, CA, leg. 559, doc. 12/12-20, el C. de Aragón, 10/4/ y 10/10/1641.

59. AGS, GA, leg. 1407, Benavides a Medinaceli, 15/10/1641.

60. AGS, GA, leg. 1497, el C. de Guerra, 1643.

61. AGS, GA, leg.1450, el duque de Ciudad Real al rey, 22/8/1642.

62. ACA, CA, leg. 565, doc. 12, el C. de Aragón, 10/6/1642

63. ACA, CA, leg. 565, doc. 7/3, el virrey de València, 26/4/1642.

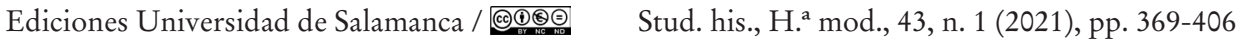


del reino» (Casey, 1983: 66), el maestre racional y nuevo alcaide de la fortaleza don Gerónimo Çanoguera carecía de reservas de trigo, al igual que la capital ${ }^{64}$, y que el gobernador de Castelló había censurado la «mala dispossición» de la población para la leva ${ }^{65}$; aunque pudo finalmente reclutarla y transportar una remonta de 2.000 caballos procedentes de Castilla y Aragón ${ }^{66}$.

\section{DE LA CONSERVACIÓN DE TORTOSA A LAS CORTES DE 1645}

El bombardeo de Vinaròs, e intento de desembarco de la flota del arzobispo de Burdeos el 26 de junio de $1642^{67}$, ha de interpretarse como un reconocimiento a la trascendencia logística que concedían las armas de Luis XIII a ese lugar. El ataque se produjo mientras cincuenta lugares de la frontera aragonesa eran arrasados y Monzón quedaba sitiad ${ }^{68}$, en una maniobra simultánea aparentemente concertada para cercenar las vías de suministro. Solo un mes antes, esa flota había combatido durante varias horas a la altura de Peníscola con seis galeones recuperados de la desventurada armada de Dunquerque, que sobrevivieron gracias a la moderna táctica de la «hilera de frente» (Hernández, 2004). No era solo el peligro exterior al que se enfrentaba la frontera. Después de tres años ininterrumpidos de alojamientos, y con la guerra a las puertas, la paciencia de los vinarossencs se tambaleaba. A finales del verano, el consistorio enumeró las consecuencias de su condición de plaza de armas y villa fronteriza para justificar una petición de ocho cañones y un permiso para construir un baluarte en la playa ${ }^{69}$, al tiempo que desembarcaron 600 soldados de la malograda guarnición de Perpignan, rendida en septiembre, que halló un recinto urbano atestado de soldados según el juez Juan Bautista Polo ${ }^{70}$. Los vecinos habían cedido enseres al hospital militar (ampliado en 1645) ${ }^{71}$ y concedido dinero a las tropas, a la vez que asistían a la pérdida de cultivos, ganado, carretas y mulas por los pillajes de migueletes y franceses ${ }^{72}$.

64. ACA, CA, leg. 722, doc. 31-1, el virrey de València al rey, 28/4/1642.

65. ACA, CA, leg. 565, 7/5, el virrey, 22/4/1642.

66. ACA, CA, legajo 111/4, el Consejo de Aragón al rey, 18/3/1642.

67. AMV (Archivo Municipal de Vinaròs), carpeta O-16, folio suelto. El episodio se recoge también en: J.M. Borràs Jarque, Historia de Vinaròs, Associació Amics de Vinaròs (1974), p. 154.

68. ACA, CA, leg. 565, doc. $1,1642$.

69. ACA, CA, leg. 883, doc. 70/1-8, el C. Aragón al rey, 6/11/1642.

70. ACA, Nobleza, Osuna, 18/19, doctor Polo, 10/10/1642 y AGS, leg. 1449, el virrey a Cárcamo, 30/9/1642 y Clemente Soriano a Cárcamo, 30/9/1642. Entre ellos un tercio de valones y dos tercios de irlandeses con sus mujeres.

71. AGS, leg. 1601, el virrey Arcos, 11/10/1645.

72. ACA, CA, leg. 70/1, el C. de Aragón al rey, 6/11/1642. ACA, CA, leg. 890, el C. de Aragón al rey, noviembre 1645.

Ediciones Universidad de Salamanca / అ@@ Stud. his., H. ${ }^{a}$ mod., 43, n. 1 (2021), pp. 369-406 
Ese otoño, Vinaròs vivió su consagración como clave de bóveda logística en la fase más determinante de la guerra tanto en Cataluña como en Europa, pues los ejércitos de las dos ramas de la Casa de Austria se hallaban esos meses a merced de sus antagonistas (Negredo del Cerro, 2016: 273). La Junta de Ejecución sancionó y renovó el 26 de septiembre la Junta presidida por Diego de Eraso, a la que se incorporó como secretario Bernardo de Miera, y como consejeros don Diego Fajardo (del Consejo de Guerra), el flamenco Charles de Bonnières, barón d’Auchy, ex embajador en Polonia y consejero de estado. Completaba la estructura administrativa un oficial mayor de la veeduría general, un comisario de muestras, un segundo oficial, el contador y un oficial, el tesorero general, un tenedor de bastimentos y su ayudante, el mayordomo de la artillería y su ayudante, más otro reformado. Se esperaba que colaborasen con el gobernador del cuartel, don Rodrigo de Borja Llançol y Olivera, perteneciente a una rama secundaria de la saga ducal ${ }^{73}$, quien sustituirá a Eraso por fallecimiento en $1645^{74}$. Tras la defenestración de Olivares en enero de 1643 y la purga de Juntas, la composición esencialmente técnica y no cortesana la librará de la extinción, como en otros casos (Gil, 2015: 63-68), pese a que el virrey se postuló a favor, seguramente al sentir disminuida su autoridad y la del veedor general que le asistía.

Superada en el verano de 1643 la acometida francesa sobre Tarragona, comenzó en València la negociación para prorrogar durante un año el fenecido servicio de 1626, como lo había hecho antes Aragón ${ }^{75}$. El acuerdo permitió a la corona disponer de 1.200 hombres durante la primavera de 1644 para reforzar Lleida (recuperada en julio) y otros mil para defender Tarragona, que resistió en septiembre (Vila, 1983: 35). El cambio de la situación militar en Cataluña aplacó la ininterrumpida presión que desde 1639 habían sufrido las tropas de Felipe IV en ese frente, que todavía lograban mantener enfrentamientos simultáneos en Flandes, norte de Italia y Portugal (Maffi, 2014: 522-523). Sin embargo, los perjuicios para la sociedad local no experimentaron cambios. El ejército real no se movía de la frontera oriental aragonesa hacía más de un año, de manera que se resolvió alojar parte de sus contingentes en el reino de Valencia con la voluntad de aliviar una tierra devastada. Desde febrero de 1645 la mayor parte de la caballería (de las Órdenes, las guardas viejas y napolitanos) y 1.500 infantes acamparon en Sant Mateu y los municipios colindantes; unas «vecindades acabadas $\gg^{76}$ a las que se exigió acarrear con casi todo el coste de un sustento ${ }^{77}$ que se

73. AHN, OM, Exp. 1178, caja 224. Su padre, Baltasar de Borja, fue gobernador de Ibiza.

74. AGS, GA, leg. 1512, el virrey al rey, 30/8/1643.

75. ACA, CA, leg. 564, doc. 11/64-62, el duque de Arcos, 27/5/1643 y C. de Aragón, $12 / 6 / 1643$.

76. AGS, leg. 1610, el virrey Arcos, 11/4/1645.

77. ACA, CA, leg. 889, 73/1, el Consejo de Argón al rey, 1645, AGS, GA, leg. 1600, el virrey Arcos, 24/2/1645. 
prolongó más de lo anunciado (Vila, 1983: 54). Cuando abandonaron el territorio en mayo, un regimiento recién llegado de alemanes, que «no son fáciles de contentar», y reclutado inicialmente para presidiar la malograda $\operatorname{Rosas}^{78}$, se alojaba en el Maestrazgo, justo cuando los franceses atacaron el frente occidental catalán. El virrey, duque de Arcos, al augurar «la ruina y más fatal suceso deste reino...» ${ }^{79}$, se personó en Vinaròs para su defensa, mientras la malla de caminos del interior castellonense recuperaba los tránsitos, como los de las compañías de don José Otio, don Pedro de Acuña y don Antonio Luna que descendieron al litoral desde las alturas de Castellfort (Miralles, 2002: 87), trece compañías de refugiados de Rosas, que acamparon en Catí, seguramente en su camino a Aragón (Camarero: 2015:249), aldea donde se encerró a franceses rendidos de Flix, o los alemanes que procedentes de Vinaròs estacionaron en el bosque de Vallibana (Puig, 1998: 29-30), entre Xert y Morella.

En el escenario europeo las victorias que en 1645 condujeron a los suecos hasta las puertas de Viena, salvada casi de milagro, supusieron un punto de inflexión que estimuló las negociaciones de paz en Westfalia (Wilson, 2008: 692). En el contexto valenciano las Cortes se desarrollaron con el frente estabilizado tras la recuperación española de la barrera que constituía el perímetro Lleida-Balaguer y la preservación de las plazas tarraconenses. La corona renovó entonces el reclutamiento ordinario de levas (1.200 hombres durante seis años) y las villas reales aprobaron decenas de medidas relativas a la defensa (Guia, 1984: 45). Pero no todos los valencianos vivían esos meses con la solemnidad de aquellas reuniones. Una leva de 800 hombres apostada en Castellote se deshizo en la estepa turolense, y varias falanges de los 12.000 hombres que se encaminaron ese verano hacia Cataluña a través de los pasos de Molina de Aragón, Ágreda y Requena (Camarero, 2015: 248, 273) tuvieron necesariamente que ser atendidas a lo largo de las exhaustas poblaciones del «camino valenciano». Dando cuenta al rey Planeta de lo sucedido hasta ese año Peníscola y Morella suplicaron que se proscribieran las exenciones alegadas por los privilegiados para evitar alojamientos (Guia, 1984: 314, 356). Castelló de la Plana solicitó que se computaran con justicia los gastos por las continues leves que se han fet en lo present regne des de lo any 1636 ençà per a socorro dels reals exèrcits. Morella los cifró en 1.560 libras por alojamientos más otras 4.517 para la custodia de la Tinença de Benifassà, Vinaròs y Peníscola, sin contar los dispendios de particulares (Guia, 1984:312, 323). El clamor se reprodujo en otras ciudades: Vila-real (densamente transitada) se sentía «vejada», y Peníscola, apartada de toda ruta terrestre de consideración, pero igualmente frecuentada por las tropas, quiso proscribirlos. Capdet clamó porque solo en tres días se habían alojado allí 1.000 caballos y 2.000 infantes. A su síndico le resultaba inconcebible que la tropa excediese el número de vecinos y demandó una cuota para desterrar los abusos de los bagajes (también en las aldeas de su término

78. AGS, leg. 1608, Rodrigo de Borja, 17/7/1645.

79. AGS, GA, leg. 1610, el duque de Arcos al rey, 17/4/1645.

Ediciones Universidad de Salamanca / అ@@ Stud. his., H. ${ }^{a}$ mod., 43, n. 1 (2021), pp. 369-406 
general) de manera que no fuera mayor a uno por cada veinte casas (Guia, 1984: $318,331,352,381$ ). Reivindicaciones similares concertaron también a municipios de las rutas secundarias del Maestrazgo como Atzeneta, Vistabella y Benafigos ${ }^{80}$.

\subsection{El auxilio de los jueces al ejército}

A la altura de 1645, gran parte de los augustos togados de las reales audiencias y el Consejo de Aragón eran veteranos en conducciones y logística. Sus colegas castellanos no les iban a la zaga. El oidor don Gerónimo de Fuenmayor se presentó en junio de 1641 en Vinaròs con un contingente de tropas después de haber cruzado la meseta desde Madrid ${ }^{81}$. Nada les hubiera hecho sospechar tan solo unos pocos años antes que, a sus acostumbradas investigaciones en el mundo rural contra el crimen y la corrupción, iban a agregarse tareas propias de la milicia. Ni siquiera durante la portentosa operación para la expulsión de los moriscos se les exigió su asistencia. Los comisarios aragoneses pertenecían a la nobleza y la oligarquía local (Lomas, 2008: 188) y esa fue la norma general en València pero ninguno era magistrado. A comienzos del decenio de 1630 se había podido ver a algunos oidores valencianos solicitar donativos, pero sus desempeños en interés del ejército real se diversificaron en la misma proporción que se acrecentaba el desafío de Francia, motivo por el que Matías de Bayetolá, regente del Consejo de Aragón, recibió el encargo de acudir al Principado para reclutar tropas en 1635 (Elliott, 2016: 326). Que esa experiencia fuera inaudita era congruente, sin embargo, con la obligación de un ministro real que, como consejero, debía auxilio tanto al monarca como al virrey en tiempos de guerra (Canet, 1990: 26-27). En la hora decisiva de Felipe IV nadie como un juez de la Audiencia, que simbolizaba y era - en palabras de Elliott - la administración real (2016: 107), podía ejercer mayor autoridad para hacer cumplir las órdenes del rey. Nada tenía de particular, por ejemplo, que Eraso y Cárcamo identificase entre los miembros de la Junta de guerra de Vinaròs a Pedro Villacampa como oidor del Consejo Real ${ }^{82}$. Es una ambivalencia que Pere Oromig pintó en 1613 (fig. 3) en lo que constituye un testimonio de la participación excepcional de un juez en asuntos encargados al ejército, junto al virrey y el general Mexía (Villalmanzo, 1997: 52).

La orden del 20 de julio de 1636 que exigió al oidor de corte Pedro Rejaule conducir desde Requena, junto al consejero de guerra Bartolomé de Anaya (ejemplo de la implicación de los consejeros de la Monarquía), una recluta de 1.480 milicianos hacia Los Alfaques, fue una de las múltiples disposiciones de ese tenor que comenzaron a recibir los togados. El rey justificó la comisión porque cabía prevenir «todo

80. AHN, OOMM, libro 535, ff. 124v-125r.

81. AGS, GA, leg. 1388, el Consejo de guerra al virrey de València, 18/4/41.

82. AGS, GA, leg. 1462, Eraso al rey, 1642. 
FIg. 3. El oidor civil Francisco Pablo Vaciero (a la izquierda de la imagen) durante la expulsión de los moriscos

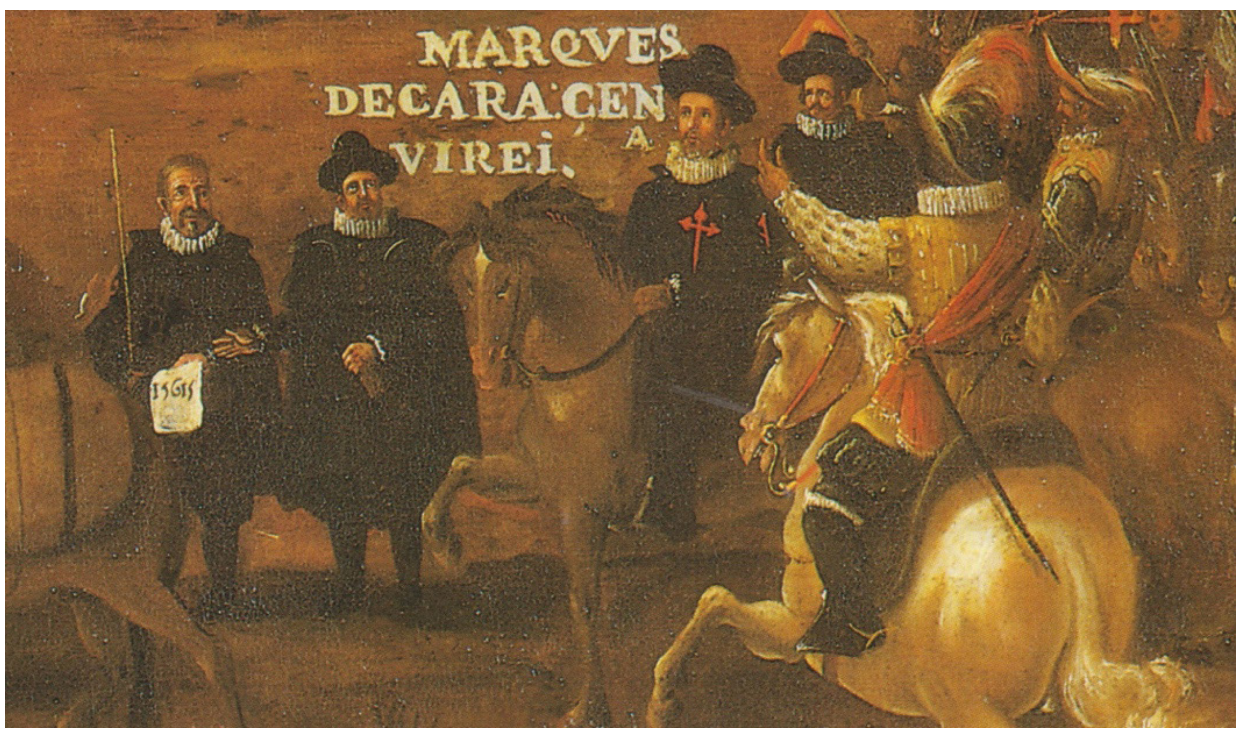

Fuente: detalle de la pintura Embarque de los moriscos en el Grau de Valencia.

lo que pueda ocasionar a encuentros entre la gente de guerra y los de la tierra, y que los alojamientos se hagan con igualdad...»; toda una declaración de realismo preventivo. Cuando la expedición de Rejaule alcanzó Quart, los jueces de corte Francisco Sancho y Vicente Miquel se incorporaron a la expedición hasta llegar a la raya, donde dos jueces de la audiencia barcelonesa tomaron el relevo. En los primeros días del año siguiente, Rejaule se puso de nuevo al frente de una conducción como si de un avezado comisario se tratase ${ }^{83}$, aunque su falta de formación jurídica e indolencia le facilitó una «jubilación forzosa» (Canet, 1990: 137) que posiblemente agradeció. En 1639, al igual que sus colegas catalanes convertidos en «oficiales de reclutamiento y proveedores» (Elliott, 1998: 619) los valencianos Pedro Villacampa y Gregorio Mingot, abogado fiscal, recibieron la tediosa comisión de incautar y transportar forrajes. Al juez de corte Francisco Bono no le fue mejor. Se le asignó la extravagante misión de supervisar la fabricación de pólvora y acaudillar la recluta de la leva de poniente ${ }^{84}$. Ese año, los aragoneses Aragón Vicente Hortigas, oidor

83. ACA, CA, leg. 891, doc. 3/1-3/14.

84. ACA, CA. leg. 558, doc. 4/34, el virrey al Consejo de Aragón, 29/8/1639. 
civil, y Miguel Jerónimo Castellot, oidor criminal, y los valencianos Pedro Sanz, oidor civil y Miguel Jerónimo Sanz, juez de corte ${ }^{85}$, persuadieron a la población para incorporarse a las levas:

[...] para hacer todas y qualesquiere diligencias que convenga y sean necesario en orden a que las universidades y particulares de la provincia acudan conforme a su obligación (...) Y para poder compeler y castigar a los que no lo hicieren y asimismo para la condución de víveres, forrajes y acarretos, camas, municiones y otros qualesquier géneros y provisiones necessarias y demás assistencias para el exército... ${ }^{86}$.

Uno de los juristas que más había puesto a prueba sus capacidades fue el oidor valenciano de la Junta de Vinaròs, Pedro Villacampa. Durante el socorro de Salses alojó en Peníscola la leva de 1.200 hombres para que embarcase en la escuadra genovesa; en mayo del año siguiente reanudó sus tareas de comisario, junto a otros magistrados, para recibir en la raya las tropas castellanas y portuguesas reclutadas durante los días de los disturbios en el campo catalán ${ }^{87}$. Alojó el ejército de los Vélez en Morella y lo guió hasta Tortosa, asistió a Leganés y contrató albañiles para las fortificaciones catalanas y las fábricas de bizcocho de Rosas, Tarragona, Tortosa y Morella. Entre otras variopintas tareas se dedicó a contratar calafates para las galeras de España en Cartagena ${ }^{88}$. Durante la onerosa retirada de los Vélez, socorrió Tortosa y se responsabilizó de la infantería y caballería de las milicias, tres compañías de la Costa y otras dos que llegarían desde València ${ }^{89}$. Continuó sus servicios durante el cerco a Tortosa de 1642 y a esas alturas Vinaròs podía considerarse su segundo hogar: «muchas son las veces que he hecho ese viaje, y la última cuando el marqués de Leganés, a quien asistí en las cosas del exército» ${ }^{90}$. En noviembre de 1642 ascendió a oidor civil (Canet, 1990: 172) y fue llamado a la capital. Villacampa era favorito del arzobispo de València y su influencia puede explicar, como en el caso de otros magnates, que ascendiera al Consejo de Aragón en 1645 (Casey, 1983: 204). Pero su excelente carta de servicios militares pesó, con seguridad, en la justificación de los méritos, recompensados un año más tarde con un hábito de Montesa (Cerdà, 2014: 294). Otros oidores se pusieron al frente de conductas en el frenético año de 1642.

85. ACA, CA, leg. 558, doc. 4/68, el Consejo de Aragón al rey, 12/10/1639. El virrey expresaba su pesar porque en los últimos meses ascendían a 3.700 hombres los que el reino había levantado para asistir en Salses e Italia. ACA, CA, leg. 557, doc. 13/11, el Consejo al rey, 19/12/1639.

86. ACA, CA , leg. 558, doc. 4/62, el Consejo Aragón al rey, octubre 1639.

87. ACA, CA, leg. 719 , doc. $67 / 2$, el virrey, 8/5/1640.

88. El memorial completo de Villacampa está publicado en el apéndice documental n. ${ }^{\circ} 19$ de la tesis doctoral de Arrieta Alberdi, (1987), «El Consejo Supremo de la Corona de Aragón (1497-1707)», Universitat de Barcelona, a quien agradezco esta valiosa información.

89. AHN, Nobleza, Osuna, exp. 554, doc. 235.

90. ACA, CA, leg. 136, Villacampa al rey, 15/10/1642.

Ediciones Universidad de Salamanca / అ@@ Stud. his., H. ${ }^{a}$ mod., 43, n. 1 (2021), pp. 369-406 
Así lo hicieron los jueces de corte Miguel Jerónimo Sanz ${ }^{91}$, que permaneció en la frontera ese verano ${ }^{92}$, y Francisco Bono ${ }^{93}$, a quien le quedó el consuelo de recibir el título de caballero al año siguiente por su diligencia en la persecución de delincuentes, pero también por su contribución a la leva (Canet, 1990: 245). El regente de la cancillería valenciana, Juan Jerónimo Blasco, alegó los achaques de sus 73 años de ancianidad, y 35 años de servicio, para no acudir ${ }^{94}$. Fue sustituido en octubre por el oidor civil Juan Bautista Polo, quien colaboró con el gobernador del cuartel de Vinaròs, Rodrigo de Borja, y la Junta en el alojamiento de los infantes de Perpiñán en septiembre ${ }^{95}$. Aunque desconocemos si don Antonio Juan de Centelles realizó tareas semejantes, su nombramiento como juez de corte en diciembre (Canet, 1990: 209) es posible que estuviera avalado por sus servicios durante las levas del conde de Oliva, de quien era familiar, en el decenio anterior.

Las peripecias que sorteó el prestigioso jurista y oidor civil valenciano Cristóbal Crespí de Valldaura son el paradigma de la nueva y azarosa vida que experimentó ese grupo profesional. Su alto escalafón en la jerarquía de la Audiencia no le eximió de levantar en 1637 una leva de caballería a instancia del Consejo de Aragón, que se comprometió a conseguir «lo que Vuestra Magestad le offresce en premio de lo que sirviere ... ${ }^{96}$, augurando un rosario de futuras mercedes. La rebelión del Principado, como a sus colegas, le sumergió en inusitados menesteres, como trasladar secretamente la artillería de Segorbe a Teruel en 1640 bajo un implacable sol de agosto ${ }^{97}$. Dos meses después fue uno de los ministros reales que escudriñaba en los lugares del Maestrazgo en busca de forraje para los tercios de los Vélez ${ }^{98}$. Al año siguiente contribuyó al suministro de la pólvora como asentista. Durante todo el verano de 1642, amenizado por monótonas cigarras en el paso de Siete Aguas, languidecía aguardando tránsitos que llegaban en pequeños grupos. Con profundo hastío escribió al Consejo de Aragón para recordar que su única ocupación consistía en conducir «tropillas» como cualquier justicia ordinario 99 . Pero los anunciados premios comenzaron a llegar. Ese mismo año ingresó como regente del tribunal supremo de la corona aragonesa, al igual que el también valenciano Lamberto Ortiz y el aragonés Jacinto Valonga. El primero había desarrollado labores de espionaje

91. ACA, CA, leg. 35/2, Don Rodrigo de Herrera al virrey, 22/4/1642.

92. AGS, GA, leg. 1367, Garay al duque de Cardona, 20/6/1640.

93. ACA, CA, leg. 7/5, el Consejo de Aragón al rey, 22/4/1642 y 7/6, Bono al virrey, 21/4/1642.

94. ACA, CA, leg. 722, doc. 43/2, Blasco al rey, 7/7/1642.

95. ACA, CA, leg. 722, 43/4-5, el virrey al rey, 5/10/1642. AGS, GA, leg. 1449, el conde duque a Cárcamo, 30/9/1642.

96. ACA, CA, leg. 556, doc. 14/15, el Consejo de Aragón al rey, 12/4/1637.

97. ACA, CA, leg. 555, 8/23, el Consejo de Aragón, 21/8/1640.

98. AGS, leg. 1413, Cárcamo, 5/11/1641. AGS, GA, leg. 1362, el virrey al rey, 19/10/1640.

99. ACA, CA, leg. 564, doc. 11/67, Crespí al rey, 15/12/1642. 
en Cataluña y el segundo se incorporó a la administración militar de los Vélez en Tarragona como auditor general. Al año siguiente, el aragonés Vicente Hortigas ocupó el cargo de regente de la Audiencia de Aragón y del Consejo de Aragón gracias, en parte, a sus desvelos en las conducciones de 1639 (Arrieta, 1994: 614).

En febrero de 1643 el Consejo de Aragón comprendió que el trabajo de Crespí en la raya con Castilla «no pide la assistencia de tanto ministro» y le encomendó la información contra el gobernador de Tortosa, Antonio Saavedra. Concluida la misión se le permitió volver a Madrid ${ }^{100}$, donde consolidará una fulgurante carrera al ser nombrado ese mismo año regente del Consejo de Aragón (Canet, 1990: 171). En 1644 accedió a la asesoría y clavería de la Orden de Montesa, concentrando en torno a sus distintos cargos un inmenso poder al controlar las concesiones de hábito de una Orden que su hermano Juan dirigía como lugarteniente general (Cerdà, 2014: 289-293). Al año siguiente acudió a las Cortes valencianas como primer letrado regio. Nada más acabar la guerra de Cataluña su carrera se coronó con el oficio de vicecanciller, aunque hacía tiempo que políticamente se consideraba a sí mismo como un «valido» para los reinos de la Corona de Aragón (Arrieta, 2019: 252-258). Al oidor valenciano Antonio Ferrer y Díaz, algo más joven que los anteriores, también le valieron sus servicios en la guerra para ascender a juez de corte (1645), oidor de causas civiles (1651) y regente de la Cancillería (1660) (Canet, 1990: 174). No cabe duda de que los doce oidores valencianos, y otros aragoneses, de los que conocemos su intervención en la administración militar tuvieron la oportunidad de engrosar sus méritos y promocionarse hasta incluso el Consejo de Aragón gracias a sus servicios para el ejército (Arrieta, 1995: 184).

\section{CAÍDA DE TORTOSA E INVASIÓN DEL MAESTRAZGO (1649)}

Desde la pérdida de la plaza de Rosas en mayo de 1645 la preocupación de la corona se trasladó a la conservación de Tarragona (Camarero, 2015: 357). Ese era el destino de la vasta operación de conducción de granos que comenzó en febrero de 1646 bajo la dirección del caballero y juez de corte valenciano Victoriano Calahorra, servicio que seguramente estuvo detrás de su ascenso en julio del año siguiente a oidor civil (Canet, 1990: 174). Como buen conocedor de aquella región, pues había asesorado al gobernador de Castelló de la Plana ${ }^{101}$, su intervención fue inestimable al negociar con las comunidades locales ${ }^{102}$. Sin amenazas a la vista, la Junta de Vinaròs se dedicó a la provisión de Tortosa y Tarragona, así como de la única ayuda extranjera

100. ACA, CA, leg. 564, docs. $11 / 67$ y 11/21.

101. AGS, leg. 1635, Rodrigo de Borja Llansol, 15/2/1646. Al menos fue asesor durante 1638: ACA, CA, leg. 886, doc. 111, Gerónimo Valls, 8/6/1638.

102. AGS, 1638, Oropesa al rey, 3/9/1646.

Ediciones Universidad de Salamanca / 요 Stud. his., H. ${ }^{a}$ mod., 43, n. 1 (2021), pp. 369-406 
que recibió el ejército real ese año: un tercio de los incombustibles napolitanos a los que acompañaban 500 veteranos españoles (Camarero, 2015: 280). Por otro lado, la leva de 1646 marchó sin novedad hacia Tortosa con el gobernador de Castelló a la cabeza (Guia, 1980: 137). La campaña, como en el resto de frentes europeos, se desarrollaba ya con la aspiración compartida, por casi todos, de consolidar o aumentar las posesiones territoriales y negociar, en mejores condiciones, un próximo acuerdo de paz (Negredo del Cerro, 2016: 295, 298).

El virrey, conde de Oropesa, hubo de lidiar, sin embargo, con un conflicto de primer orden: la reactivación de la lucha oligárquica entre parcialidades asistidas por el bandolerismo, que convirtió la política en un avispero de «malcontentos» y/o «desafectos» cuyos sospechosos propósitos, muchos infundados, ocuparon las sesiones del Consejo de Aragón. No era, desde luego, la primera vez que los privilegiados, y la sociedad valenciana, observaban con ácida crítica la actitud de los ministros reales, como se desprende de los pasquines y protestas estudiantiles que en 1626 parecían responder a las noticias que llegaban a València sobre el desarrollo de las Cortes de Monzón (de Lario, 1988: 167-179). El virrey reaccionó activando la vía económica sin haberse resuelto el asunto de las decretatas, la sanción regia de los fueros y actos de corte, innegociable para los estamentos. El descontento de la oligarquía alcanzó en ese momento una cota inaudita (Guia, 1980: 37,45,133) y pareció deslizarse hacia una situación «prerrevolucionaria» a finales de 1646 por el divorcio entre la deriva absolutista del virrey y la defensa a ultranza que los poderosos clanes de la ciudad ejercían de sus privilegios (Casey, 1970: 173; 1983: 171). La animadversión de esos meses fue la más parecida a la que se había conjurado social y políticamente en Cataluña en 1640, espoleada cuando caiga Tortosa en manos francesas (julio de 1648) y la oposición al virrey disponga de un magnífico pretexto para endurecer sus condiciones. En la frontera, desde Morella a Peníscola, pasando por el Maestrazgo, una tupida red de intereses clientelares, engarzada en un sistema clientelar general que explica la consistencia de la Monarquía (Borreguero, 2018: 141-146), actuará de muro de contención ante las fuerzas centrífugas, sobre todo de índole económica, que desgarraban el territorio. Nos referimos a las recompensadas ambiciones de caballeros y religiosos montesianos (muchos de ellos oriundos de las localidades afectadas), la pequeña nobleza y una miríada servicial de plebeyos ávida de privilegios y un estatus de nobleza (Hernández, 2018a). Pese a las presiones a las que se había sometido a la sociedad local, con ejemplos particulares ya citados a los que se podría sumar el de un campesino de Canet lo Roig acusado de desacato en marzo de 1646 por clamar a diario contra el latrocinio de la soldadesca ${ }^{103}$, los intereses de la oligarquía local primaron sobre cualquier otra consideración.

103. ARV, Clero, leg. 897, caja 2361-62, Procés de la vila de Canet..., 1647.

Ediciones Universidad de Salamanca / 요 Stud. his., H. ${ }^{a}$ mod., 43, n. 1 (2021), pp. 369-406 
A diferencia de lo que había ocurrido en los tres años anteriores, la campaña de 1648 comenzó con noticias muy adversas. Se temía un avance galo hacia Tortosa, plaza que los valencianos no estaban en condiciones de presidiar a causa de la peste que asolaba el sur. Las bandosidades absorbían la capacidad de acción de la milicia del Batallón ${ }^{104}$, y la oposición al virrey redoblaba sus exigencias frente al asunto de las decretatas, ahondando en la crisis constitucional ${ }^{105}$. Tratando de abstraerse, el juicioso conde de Oropesa alertó de las nefastas consecuencias de que se consumara la ofensiva francesa mientras València se consumía en una batalla política: «va caminando esta república a un precipicio...» ${ }^{106}$. La alegoría podría haber servido para describir el estado de las arcas municipales ${ }^{107}$. Del servicio previsto de 40.000 libras solo se logró recaudar 6.000 en préstamos gracias a los prohombres locales ${ }^{108}$ y las Órdenes de Montesa, Calatrava y Santiago, que aportaron $15.600,3.400$ y 2.800 ducados respectivamente ${ }^{109}$. La razón de la donación no podía haberla explicado mejor el regente conde de Albatera. Las Órdenes estaban implicadas en la conservación de sus encomiendas ${ }^{110}$; con mayor motivo Montesa, con su Maestrazgo expuesto a las invasiones.

El fatal vaticinio del virrey se consumó cuando Tortosa fue expugnada insospechadamente el 12 de julio de 1648, aunque no era impensable algún descalabro en el frente catalán si tenemos en cuenta que la maquinaria de guerra se proyectó ese año sobre Flandes, Sicilia y Nápoles aprovechando la situación interna de Francia (Camarero, 2015: 378, 383). Ahora los franceses disponían de un trampolín para lanzarse sobre un territorio con «alteración de los ánimos» al que habían llegado las noticias de las rebeliones italianas (Guia, 1980: 111). En el aparente torrente de lealtades que congregaba el norte valenciano las aguas fluían, sin embargo, algo turbias. El mayor oligarca de Castelló de la Plana, el doctor Jaume Giner, había llamado la atención por «desafecto» en las últimas Cortes (Arroyas, 1989:119) y no dejó de preocupar a la administración real cuando en mayo de 1647 fue detenido al portar dos pistolas, buscando la protección del obispado, por lo que fue excluido de las listas de insaculados. Para el gobernador, no había en su jurisdicción «perçona más opósita ni contraria al real servicio, fiado en la mano que tiene en el gobierno de esta villa y en otras donde es asesor...» ${ }^{111}$. Es probable que Giner contara con

104. ACA, CA, leg. 605 , doc. $4 / 27$, el virrey, 11/6/1648.

105. ACA, CA, leg. 570, 12/26, el virrey, 22/3/1648.

106. ACA, CA, leg. 570, doc. 12/27, el virrey, 12/3/1648.

107. ACA, CA, leg. 730, doc. 46/1, memorial del síndico de Vinaròs, 1648.

108. ACA, CA, leg. 605, doc. 25/48, el virrey, 25/8/1648 y doc. 37, el virrey, 13/9/1648.

109. ACA, CA, leg. 605, doc. 25/26, el Consejo de Aragón, 18/8/1648.

110. ACA, CA, leg. 605, doc. 25/24, el Consejo de Aragón, 13/8/1648.

111. ACA, CA, leg. 725, doc. 76/1, Vicente de Borja, 25/5/1647; 76/3, el virrey Oropesa, 6/8/1647.

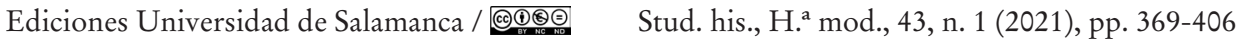


complicidades en las poblaciones donde había tejido intereses clientelares, pero nadie se atrevió a iniciar un movimiento subversivo. Acabó aceptando aparentemente la situación y se integró en el gobierno local. Morirá de un arcabuzazo en mayo de 1655 cerca de la cárcel local. Solo un mes y medio después le ocurrió lo mismo a don Bautista Vallés, subrogado del gobernador (Gimeno, 1984: 189). La coincidencia en el tiempo de esos asesinatos podría interpretarse como un ajuste de cuentas tras dos decenios de insaciables demandas a la sociedad castellonense con motivo de la guerra, al menos, desde la muerte del alguacil de la leva en 1640.

La rebelión sí mantenía partidarios entre los monjes catalanes del cenobio cisterciense de Benifassà, en la boscosa frontera interior. Al calor de la expugnación de Tortosa, una supuesta conspiración urdida por los frailes oriundos del Principado contaba, al parecer, con cómplices en el Maestrazgo y Morella. Fue probablemente una reactivación de la conjura tramada ocho años antes en el contexto del avance de La Mothe hacia Tortosa, con la participación de un conventículo subversivo de frailes y catalanes seglares que proporcionarían apoyo a la confabulación desde la parte valenciana de la raya (Camarero, 2015: 174). La intención en 1648 era precipitar la caída de Morella utilizando los ardides de un taimado fraile lego de Vinaròs, frey Juan Roca, acusado de entrevistarse con el duque de Luy y personajes de la ciudad condal. El virrey concedió credibilidad a la información y ordenó que las aldeas de Morella trasladaran a ese castillo víveres, terraplenasen las puertas y resistieran con sus propios medios porque el ejército de Aragón de Francisco de Melo no se iba a mover.

Resuelto a atajar el conciliábulo, Oropesa solicitó un listado con el origen de los frailes ${ }^{112}$ ante la convicción de que los catalanes estaban involucrados. De los treinta y tres religiosos trece eran naturales de Tortosa, incluyendo el abad y el prior, y ocho procedían de otras partes del Principado, en total veintiún catalanes. Otros seis eran naturales de Vinaròs y, entre los seis restantes, había otros valencianos y aragoneses. Oropesa ordenó que los frailes catalanes, «testigos de nuestra flaqueça», fueran trasladados a otras partes del reino o Aragon ${ }^{113}$, mientras llegaba al monasterio el rumor de que gente armada de Morella se dirigía hacia allí, desatando el pánico entre la comunidad religiosa. Su abad, fray Benito Calderón, perjuró la fidelidad del convento y arrancó un compromiso para evitar la ocupación ${ }^{114}$. La súbita muerte del superior dio alas a los implicados, que convocaron capítulo para escoger un «sujeto de la facción de Cataluña» ${ }^{115}$. El virrey, finalmente, aceptó la solución del

112. ACA, CA, leg. 559, doc.18/5.

113. ACA. CA, leg. 559, doc. 18/2, el virrey al rey, Sant Mateu, 28/9/1648, doc. 18/6. El virrey al rey, València, 14/11/1648.

114. ACA. CA, leg. 559, doc. 18/4. El virrey al abad de Benifaçà, Sant Mateu, 24/9/1648.

115. ACA. CA, leg. 559, doc. 18/6. El virrey al rey, València, 14/11/1648. 
vicario general, opuesto a la diáspora, que alegó la inoportunidad de dispersar a los frailes tras haber estallado revueltas en Francia (la Fronda) y vislumbrarse la recuperación del Principado: "no sería conveniente agitar los ánimos de los catalanes con la expulsión de frailes de esa nación...» ${ }^{116}$. Era una opinión acertada, resultado además de la reevaluación estratégica que siguió a la liberación de recursos destinados a Flandes tras el armisticio de enero de 1647 y el inicio de conversaciones de paz (Wilson: 2009: 722).

Con la más que probable intervención del virrey, el nuevo abad fue elegido entre una terna de dos valencianos y un tortosino, considerado este por el Consejo de Aragón el postulante ideal por su demostrada lealtad. Había regido la abadía cuatro años desde el 14 de septiembre de 1640, permitiendo el alojamiento del ejército real y la pernoctación de los oficiales en las celdas, siendo recompensado con 200 escudos de pensión ${ }^{117}$. El episodio había destapado, por tanto, la existencia de dos facciones entre los bernardos, siendo la mayoritaria la protectora de los migueletes durante escaramuzas como la de 1642 (Miralles, 2002: 85). Todavía en abril de 1650 un informante de Zaragoza, Juan de Raz, acusó a la facción díscola, liderada por frey Aloy Gallo de Flix, prácticamente de traición al considerarlos «más reveldes que nunca, porque favorezen tanto al francés que no hay noche no admitan en el convento su cuadrilla de michaletes...» ${ }^{118}$. El monasterio había sido objeto de sospechas desde el inicio de la contienda, cuando rechazó la reforma del convento por «cosas convenientes a la real corona», probablemente relacionada con la introducción de los acuerdos tridentinos, cuestión que dividía a los monasterios y conventos catalanes porque constituía una alteración de sus costumbres (Elliott, 2016: 489).

A la caída de Tortosa le había seguido el caos en la raya: deserciones en masa entre las filas de la milicia ${ }^{119}$, movilizada por primera vez (Camarero, 2015: 387), afluencia de refugiados (incluyendo el obispo) hacia Morella y el Maestrazgo (Querol y Muñoz, 2004: 181) seguido de un ataque de caballería francesa sobre Vinaròs el 20 de agosto registrado con euforia por la propaganda francesa en la Gazzete. Una improvisada junta reunida en Sant Mateu presidida por Melo acordó levantar fortalezas reales en Traiguera y Vinaròs, aunque solo se alzará la primera (todavía

116. ACA. CA, leg. 559, doc. 18/11. El Consejo de Aragón al rey, 22/3/1649.

117. ACA. CA, leg. 559, doc. 18/12. El Consejo de Aragón al rey, 22/3/1649. Los sugetos que propone el abbad de Valldigna, vicario general de la Orden de San Bernardo de la corona de Aragón y Navarra para la terna que ha de hazer para la abbadía de Benifaçá en el reyno de Valencia.

118. ACA. CA, leg. 559, doc. 18/13. Juan de Raz al rey, Zaragoza, 2/4/1650. Citaba a los religiosos catalanes Tomas Capellanes, Roberto Cavaller, Jerónimo Corder (de misa), Clarías Mir, Mateo Monserrat, Jose Cortiella y Francisco Seguin (legos).

119. ACA CA, leg. 605, doc. 25/10. El virrey al rey, Sant Mateu, 27/7/1648. 
en pie parcialmente y testimonio de la latitud meridional que llegó a alcanzar uno de los frentes de la Guerra de los Treinta Años) con un perímetro abastionado hexagonal que protegía el recinto urbano y cubría el camino real (Hernández: 2018; 2019). Por entonces se dejaban notar en el norte del reino los efectos económicos de la epidemia pestífera: «nos estamos muriendo de hambre» clamó Vinaròs ${ }^{120}$ en un memorial que desgranó las consecuencias de los alojamientos:

...Que haviendo ido a alojarse differentes veces cavallería y infantería los han maltratado y talado su huerta haciéndose dar de comer, iriendo y ultrajándoles assí de obra como de palabra, de suerte que viendo los particulares de la villa que empobrecían afligidos y maltratados han dejado muchos dellos sus casas y haziendas, huiendo desto y de la fuerça que podían hacer a sus mujeres y hijas como se han atrevido a intentarlo... ${ }^{121}$.

Hacía siete años que Vinaròs albergaba una guarnición de un tercio de infantería y tres compañías de caballo del Rosellón de 500 hombres alimentados por los vecinos (Albiol, 2003: 36), eso sin contar las miles de tropas de naturales o de naciones alojadas temporalmente desde 1640 en el Maestrazgo: la estancia de los ejércitos reunidos en 1640 y 1642, la gran flota del verano de 1641, la remonta de 2.000 caballos en marzo de 1642, la caballería del ejército de Aragón en el invierno de 1645, más las levas anuales y las milicias que se concentraron en la frontera en 1648 así como el ejército que pronto reunirá Mortara en 1650 para la recuperación de Tortosa. Desde la caída de la ciudad del Ebro había cesado «la contratación por las invasiones que el enemigo continuamente hazía en esta frontera». En realidad, toda la economía del Maestrazgo había sucumbido a la guerra y la peste desatada en 1648, cuyas consecuencias se manifestaron durante décadas y fueron pormenorizadas por los síndicos municipales. El consistorio de Peníscola, donde tantas veces se había hecho necesario auxiliar a los soldados, se declaró en bancarrota y expuso en un memorial de 1651 los motivos (Hernández, 2006: 55):

...desde el año 1584 hasta el de 1643 ha gastado la villa en conservar la artillería, murallas, guardas y en otros gastos que ha escusado a la real hazienda más de 4.500 libras. Desde que duran las guerras de Flandes y Cataluña ha sido el paso continuo y más usado para embarcaciones de gente y pertrechos, padeciendo aun antes que ningún otro lugar del reyno los efectos de la guerra...

Pese al cúmulo de desgracias, la frontera todavía experimentó un agravamiento sin precedentes y de consecuencias dramáticas. En noviembre de 1649, tal y como

120. A.C.A. CA, legajo 727 doc 66/2. El virrey al Consejo de Aragón, Valencia, 1/6/49, doc 12/2. El síndico de Vinaròs al virrey, 22/8/1648.

121. Memorial del síndico de Vinaròs. ACA. CA, leg 605, exp 41/1 (2/8/1648).

Ediciones Universidad de Salamanca / @®@@ Stud. his., H. ${ }^{a}$ mod., 43, n. 1 (2021), pp. 369-406 
vaticinó el virrey semanas antes ${ }^{122}$, la frontera fue invadida. El ataque había sido ideado como una puissante diversion, difundida con triunfalismo por la Gazette, frente a la ofensiva española sobre Barcelona en septiembre. El mariscal Ferdinand de Marchin, gobernador de Tortosa, fue el promotor. El 1 de noviembre cruzaron la raya 1.800 infantes catalanes y franceses, más 800 jinetes galos y dos piezas de artillería, bajo las órdenes del general catalán de caballería don Josep d'Ardena, mariscal de Francia y uno de los seis nobles que habían encabezado la ruptura de Cataluña con Felipe IV. La defensa de Sant Mateu y la fortaleza de Traiguera no impidieron el paseo militar, que apuntilló a las agonizantes poblaciones del Maestrazgo. Fueron saqueadas la Jana, Carrascal, Càlig, Sant Jordi, Canet lo Roig, Xert y la más meridional villa de Salzadella (Hernández: 2013), cuyos pormenores evocan las perturbadoras escenas al paso de los ejércitos en Alsacia, Bohemia, Palatinado o Baja Westfalia entre otras regiones arrasadas por la guerra (Negredo del Cerro, 2016: 89, 107). Pocos meses después, una despoblada Salzadella consignó la cifra de 17.000 ducados en pérdidas derivadas de la guerra:

...han sido tan excesivos los daños que se han seguido a la dicha villa, assí por la invasión y saco que hicieron en ella los catalanes y franceses los días pasados, como por los continuos alojamientos y provisión de bagajes para el servicio de $\mathrm{Su}$ Magestad $^{123}$.

En el enésimo ejemplo de capacidad logística del territorio, el 19 de octubre de 1650 mil valencianos cruzaban la frontera con el ejército para asediar Tortosa, que cayó el 4 de diciembre poniendo fin a la amenaza sobre el reino. Los repudiados alojamientos, sin embargo, continuaron hasta mayo del año siguiente. El grado de irritación había llegado a tal extremo que se paralizó la leva de 1651 (Guia, 1980: 125), pero no así la participación en la ofensiva final sobre Barcelona. En 1653, Vinaròs será «otra vez, el sitio donde han de concurrir las asistencias del exército...» y las fortalezas de Cataluña ${ }^{124}$. A esas alturas las haciendas locales estaban esquilmadas por las «calamidades de guerra» ${ }^{125}$, de forma que el virrey Montalto se opuso al alojamiento de 1.750 irlandeses durante la primavera de 1654 con una declaración de impúdico realismo. Aunque los fueros se respetaran, nada podía hacerse contra el ensueño de atajar «el mal ánimo con que se conoce esta voz alojar», y sus condiciones siempre les parecerán insuficientes a los soldados, «ni podrá conseguirse jamás que se ajusten dentro de los términos sin hacer extorsiones...» ${ }^{126}$.

122. AGS, Guerra y Marina, leg. 1733, Oropesa al rey, Valencia, 16/10/1649.

123. ACA, CA, legajo 895, 54, el Consejo de Aragón al rey, 15/5/1650.

124. ACA, CA, leg. 567, doc. 10/1, el virrey, 21/7/1653.

125. ACA, CA, leg. 600, doc. 10/1-2, el rey en respuesta a un memorial del Maestrazgo, $7 / 10 / 1662$.

126. ACA, CA, leg. 557, doc. 13/37, el C. de Aragón, junio, 1654, doc. 13/38-39, Montalto, $7 / 12 / 1654$.

Ediciones Universidad de Salamanca / అ@@ Stud. his., H. ${ }^{a}$ mod., 43, n. 1 (2021), pp. 369-406 


\section{CONSIDERACIONES FINALES}

La guerra con Francia desde 1635 transformó la definición del reino de València en el entramado logístico de la monarquía hispánica en su más amplia pugna durante la Guerra de los Treinta Años. La exitosa experiencia en el socorro de Salses (1639) y la guerra de Cataluña (1640-52) convirtió sus vías de comunicación terrestre y marítima en un propicio "camino valenciano", el único corredor militar viable de la Monarquía, que sostuvo el desplazamiento de tropas, flotas, bastimentos armas y pertrechos hacia el frente catalán durante los cinco años decisivos para su supervivencia (1640-1644) y de manera determinante hasta la recuperación de Barcelona. Un profundo cambio estratégico y mental se produjo entonces en los valencianos. Por primera vez desde 1356-1369 (guerra de los dos Pedros), pese a que resultaba inconcebible a los estamentos una invasión que «no puede ser por tierra» (de Lario, 1988: 326) la Guerra de Cataluña abría un aventurado frente terrestre que promovió planes de fortificación y la construcción final de una fortaleza hexagonal en Traiguera. Por otra parte, la trascendencia de la nueva función logística del reino fue la causa de que se constituyera en Vinaròs, en el verano de 1641, una Junta de guerra consagrada en octubre del año siguiente. La presencia de esa Junta, máximo órgano sinodial de la administración militar, y la propia dinámica del conflicto con sus derivaciones políticas, fiscales, sociales y económicas cimentaron la inserción del reino de Valencia en la Unión de Armas. En el ámbito de la administración militar, a pesar de los esfuerzos de ministros y oficiales reales (incluyendo a los togados) los desafíos logísticos y financieros de la guerra exigieron la implicación de acaudalados, poderosos locales y el conjunto de la sociedad. Las consecuencias sociales y económicas del trasiego incesante de tropas y los alojamientos, que tantas protestas levantaron, afectaron singularmente al último tramo del camino valenciano, por donde también remontó la peste entre 1648 y 1649. La destrucción de parte de la frontera en noviembre de 1649 asestó un golpe casi definitivo a su capacidad de supervivencia. Fue una tragedia de una trascendencia mucho mayor, sin duda, a la que se ha atribuido hasta ahora, sobre todo al compararse con el caso aragonés. Solo la unánime adhesión de la nobleza y los sueños aristocráticos de la burguesía local evitaron que el descontento social se convirtiera en la semilla de una rebelión para la que una gran parte de los sectores populares hubiera hallado motivos más que suficientes.

\section{BIBLIOGRAFÍA}

Albiol Vidal, S. (2003). Establiments de Vinaròs. Un estudi de dret foral valencià del segle XVII. Benicarló: Centro de Estudios del Maestrazgo.

Ediciones Universidad de Salamanca / 요 Stud. his., H. ${ }^{a}$ mod., 43, n. 1 (2021), pp. 369-406 
Andrés Robres, F. (1999). La economía de la Orden de Montesa cuando la incorporación: patrimonio, renta, gasto, balances (1592-1602). Estudis. Revista de Historia Moderna, 25, 55-87.

Andrés Robres, F. (2006). Montesa y la crisis del siglo XVII: el colapso financiero de la orden militar valenciana. Revista de Historia Moderna, 24, 227-252.

Andrés Robres, F. (2019). El servicio de la Orden de Montesa a la Corona tras la incorporación: la dimensión militar y otras consideraciones (1592-1700). En Ordens Militares, identidade e mudança. VIII Encontro sobre Ordens Militares. Palmela [en prensa].

Arráez Tolosa, A. (2015). Almansa y la monarquía de Felipe IV: la villa como lugar de paso y alojamiento de tropas. En Monarquía y republicanismo en Almansa (pp. 15-61). Almansa: Ayuntamiento de Almansa,.

Arrieta Alberdi, J. (1984). El Consejo Supremo de la Corona de Aragón (1494-1707). Zaragoza: Institución Fernando el Católico.

Arrieta Alberdi, J. Vicente Hortigas, Lamberto Ortiz, Jacinto Valonga. En Diccionario Biográfico electrónico. Madrid: Real Academia de la Historia (en red, http://dbe.rah.es/).

Arrieta Alberdi, J. (2019). La Orden de Montesa en las Observationes de Cristóbal Crespí de Valldaura. En E. Guinot, F. Andrés, J. Cerdà, J.F. Pardo (Eds.), Santa María de Montesa. La orden militar del Reino de Valencia (ss. XIV-XIX) (pp. 251-269). València: Universitat de València.

Arroyas Serrano, M. (1988). El Consell de Castellón en el siglo XVII. Castelló de la Plana: Diputación de Castellón.

Borràs Jarque, J. M (1929). Historia de Vinaròs (1974). Vinaròs: reedición de la Associació Amics de Vinaròs.

Borreguero Beltrán, C. (2013). El ejército del rey. En L. Ribot (coord.), Historia Militar de España. Edad Moderna. II. Escenario Europeo (pp. 119-148). Madrid: Ministerio de Defensa.

Borreguero Beltrán, C. (2018). La Guerra de los Treinta Años, 1618-1648. Europa ante el abismo. Madrid: La Esfera de los Libros.

Camarero Pascual, R. (2015). La Guerra de recuperación de Cataluña, 1640-1652. Madrid: Actas.

Canet Aparisi, T. (1990). La Magistratura Valenciana (s. XVI-XVII). València: Universitat de València.

Casey, J. (1983). El reino de Valencia en el siglo XVII. Madrid: Siglo XXI.

Cerdà, J. (2014). Los caballeros y religiosos de la Orden de Montesa en tiempo de los Austrias (1592-1700). Madrid: CSIC.

Elliott, J. H. (1991). El conde-duque de Olivares. Barcelona: Grijalbo.

Elliott, J. H. (2016). La rebelión de los catalanes. Un estudio sobre la decadencia de España (1598-1640). Madrid: Siglo XXI.

Esteban Estríngana, A. (2013). El control y la fiscalización del gasto militar. En L. Ribot (coord.), Historia Militar de España. Edad Moderna. II. Escenario Europeo (pp. 259-284). Madrid: Ministerio de Defensa.

Ediciones Universidad de Salamanca / @®@@ Stud. his., H. ${ }^{a}$ mod., 43, n. 1 (2021), pp. 369-406 
Felipo Orts, A. (1988). El Centralismo de nuevo cuño y la política de Olivares en el País Valenciano: fiscalidad, control y hacienda municipal (1621-1634). València: Ayuntamiento de Valencia.

Felipo Orts, A. (2010). Servicios y donativos de la ciudad de Valencia a la monarquía durante la revuelta catalana. Studia historica. Historia moderna, 32, 305-333.

García Martínez, S. (1980). Bandolers, Corsaris i Moriscos. València: Sèrie la Unitat.

Gil, X. (1992). «Conservación» y «defensa» como factores de estabilidad en tiempos de crisis: Aragón y Valencia en la década de 1640. En VV. AA., 1640: la Monarquía bispánica en crisis (pp. 44-101). Barcelona: Crítica.

Gimeno Michavila, V. (1984). Del Castellón viejo. Castelló de la Plana: Caja de Ahorros y Monte de Piedad de Castellón.

Goikoetxea Beltrán, A. (2013). El retrato del duque de Saboya en un programa pictórico del Maestrazgo (Albocàcer, Castellón, circa 1590). En V. Mínguez Las Artes y la arquitectura del poder (pp. 1337-1354). Castelló de la Plana: Universitat Jaume I.

Gónzalez Enciso, A. (2008). El estado fiscal-militar, una reflexión alternativa. Memoria y civilización: anuario de historia, 271-295.

Guia Marin, Ll. (1980). La Guerra de Cataluña y el bandolerismo valenciano (1640-1652). En Actes du Ier Colloque sur le Pays Valencien a l'Epoque Moderne (pp. 117-141). Pau: Université de Pau.

Guia Marin, Ll. (1984). Cortes del reinado de Felipe IV. València: Universitat de València.

Hernández Ruano, J. (1997). La intendencia de las compañías valencianas levantadas con motivo de la crisis de Mantua (1630-1631). Saitabi. Revista de la Facultat de Geografía e Història, 47, 309-327.

Hernández Ruano, J. (2004). David contra Goliat. La batalla naval de Peñíscola en formación de hilera de frente (14 de mayo de 1642). Boletín del Centro de Estudios del Maestrazgo, 72, 45-54.

Hernández Ruano, J. (2006). Aproximación a la crisis de Peñíscola en el siglo XVII. Boletín del Centro de Estudios del Maestrazgo, 76, 53-69.

Hernández Ruano, J. (2013). Incursiones y operaciones navales franco-catalanas sobre la frontera valenciana durante la Guerra dels Segadors. La invasión de don Josep d'Ardena (noviembre de 1649). Boletín del Centro de Estudios del Maestrazgo, 89, 6-46.

Hernández Ruano, J. (2014). Poderosos pleitos. La justicia de la Orden de Montesa. El señorío de Montesa (siglos XVI-XVII). Castelló de la Plana: Universitat Jaume I.

Hernández Ruano, J. (2014a). Peñiscola inexpugnable. La fortaleza y el Mediterráneo desde Carlos V a Alfonso XIII. Vinaròs: Quatre Colors.

Hernández Ruano, J. (2018). La muralla de los estados de vuestra excelencia. La fortaleza de Traiguera y los proyectos para la defensa de la frontera valenciana (1640-1650). En I. Fortea, J. E. Gelabert, R. López, E. Postigo (Coords.), Monarquías en conflicto. Linajes y noblezas en la articulación de la Monarquúa hispánica (pp. 207-221). Madrid: Fundación Española de Historia Moderna-Universidad de Cantabria.

Hernández Ruano, J. (2018a). En busca del privilegio: el norte valenciano y el servicio a la monarquía durante el siglo XVII. En J. S. Amelang, F. Andrés, R. Benítez, R. Franch,

Ediciones Universidad de Salamanca / 요 Stud. his., H. ${ }^{a}$ mod., 43, n. 1 (2021), pp. 369-406 
M. Galante Becerril (eds.), Palacios, plazas, patíbulos. La sociedad española entre el cambio y las resistencias (pp. 577-588). Tirant Humanidades.

Hernández Ruano, J. (2019). La fortificación del reino de Valencia en la década de 1640 a la luz de la revolución militar. Estudis. Revista de Historia Moderna, 45, 197-224.

Hernández Ruano, J. (2020). La gestión de la guerra en la retaguardia. Antecedentes y formación de la junta de guerra de Vinaroz (1639-1643). En A. Jiménez, J. Castillo (eds.), La rebelión de los moriscos de Granada y la guerra en la época de los Austrias: estudios para un debate abierto (pp. 277-296). Granada: Universidad de Granada.

Hernando Sánchez, C. J. (2013). Non sufficit orbis? Las estrategias de la Monarquía de España. En L. Ribot (coord.), Historia Militar de España. Edad Moderna. II. Escenario Europeo (pp. 29-65). Madrid: Ministerio de Defensa.

Lario Ramírez, D. de (1986). El comte-dic d'Olivares i el regne de València. València: Eliseu Climent.

Lomas Cortés, M. (2008). La expulsión de los moriscos del reino de Aragón. Politica y administración de una deportación (1609-1611). Teruel: Centro de Estudios Mudéjares.

Maffi, D. (2014). En Defensa del imperio. Los ejércitos de Felipe IV y la guerra por la hegemonía europea (1635-1659). Madrid: Actas.

Maffi, D. (2019). Tiempos de calamidades. Las haciendas de Milán, Nápoles y Sicilia frente a la crisis (1630-1660). Studia Historica, Historia Moderna, 41, 29-63.

Martínez Ruiz, E. (2008). Los soldados del rey. Madrid: Actas.

Melo, F. M. (1994). Historia de los movimientos, separación y guerra de Cataluña en tiempo de Felipe IV. Valencia: librería París-Valencia (edición facsímil de la reedición de 1808 en Madrid).

Miralles I Sales, J. (2002). La villa de Castellfort. Benicarló: Centro de Estudios del Maestrazgo.

Negredo del Cerro, F. (2016). La guerra de los treinta años. Madrid: Síntesis.

Pardo Molero, J. F. (2002). La defensa del imperio. Carlos V, Valencia y el Mediterráneo. Madrid: Sociedad Estatal para la conmemoración de los centenarios de Felipe II y Carlos V.

Pardo Molero, J. F. (2002). La furia del capitán Salas: los notables de Villarreal frente a un alojamiento de tropas en 1537. Boletín de la Sociedad Castellonense de Cultura, 78(2), 561-585.

Parker, G. (1990). La Revolución Militar. Las innovaciones militares y el apogeo de Occidente 1500-1800. Barcelona: Crítica.

Parker, G. (1991). El ejército de Flandes y el Camino Español (1567-1659). Madrid: Alianza, 1991.

Pi Corrales, M. de P. (1998). Aspectos de una difícil convivencia: las guardas y los vecinos de los aposentamientos. En VV. AA., Las sociedades ibéricas y el mar a finales del siglo XVI. Tomo II. La monarquía. Recursos. Organización y estrategias (pp. 513-530). Madrid: Sociedad estatal para la conmemoración de los centenarios de Felipe II y Carlos V.

Pérez García, P. (1991). Origen de la milicia efectiva valenciana: las vicisitudes del proyecto del marqués de Denia para la creación, pertrecho y movilización de los tercios del

Ediciones Universidad de Salamanca / 요 Stud. his., H. ${ }^{a}$ mod., 43, n. 1 (2021), pp. 369-406 
reino de Valencia (1596-1604). En VV. AA., Dels furs a l'estatut. Actes del I Congrés d'Administració valenciana. De la Història a la Modernitat. València: Generalitat Valenciana.

Puig Puig, J. (1998). Historia breve y documentada de la real villa de Catí. II. Castelló de la Plana: Diputación de Castellón.

Querol Coll, E., Muñoz I Sebastià, J. H. (2004). La Guerra dels Segadors a Tortosa (16401651). Valls: Cossetània.

Ruiz Ibáñez, J. J. (2019). El final del sueño imperial: guerra y poder en Castilla tras 1635. Studia Historica, Historia Moderna, 41(1), 259-288.

Salvador Esteban, E. (1973). Cortes valencianas del reinado de Felipe II. València: Universitat de València.

Sanz Camañes, P. (2004). El peso de la milicia. «Alojamiento foral» y conflicto de jurisdicciones en la frontera catalano-aragonesa durante la guerra de Cataluña (1640-1652). Revista de Historia Moderna. Anales de la Universidad de Alicante, 22, 173-208.

Segura Barreda, J. (1868). Morella y sus aldeas: geografía, estadistica, historia, tradiciones, costumbres, industria, varones ilustres, etc., de esta antigua población y de las que fueron sus aldeas, vol. 1. Morella: F. Javier Soto.

Stradling, R. A. (1992). Europa y el declive de la estructura imperial española, 1580-1720. Madrid: Cátedra.

Tropé, H. (1983). La Orden de Montesa: estudio de las rentas de la bailía de Cervera: 1587-1623. París: Universidad de la Sorbona, París III.

Vila López, M. (1983), La reorganización de la milicia efectiva del reino de Valencia en 1643. València: Escuela Universitaria de estudios empresariales de la Universitat de València.

Vila López, M. (1979/80). La aportación valenciana a la guerra con Francia. Estudis. Revista del Departamento de Historia Moderna, 8, 125-142.

Villuga, P. J. (1546/2016), Repertorio de todos los caminos de España. Medina del Campo/ Valladolid: Maxtor.

Wilson, P. H. (2009). Europe's Tragedy. Penguin Books.

Ediciones Universidad de Salamanca / 요 Stud. his., H. ${ }^{a}$ mod., 43, n. 1 (2021), pp. 369-406 